\title{
Investigating the Relationship between Gold and Silver Prices
}

\author{
ALVARO ESCRIBANO ${ }^{1}$ AND CLIVE W. J. GRANGER ${ }^{2 *}$ \\ ${ }^{1}$ Universidad Carlos I/I de Madrid, Spain \\ ${ }^{2}$ University of California, San Diego, USA
}

\begin{abstract}
This paper analyses the long run relationship between gold and silver prices. The three main questions addressed are: the influence of a large bubble from 1979:9 to $1980: 3$ on the cointegration relationship, the extent to which by including error correction terms in a non linear way we can beat the random walk model out of sample, and the existence of a strong simultaneous relationship between the rates of return of gold and silver. Different efficient single equation estimation techniques are required for each of the three questions and this is explained within a simple bivariate cointegrating system. With monthly data from 1971 to 1990 , it is found that cointegration could have occurred during some periods and especially during the bubble and post bubble periods. However, dummy variables for the intercept of the long run relationships are needed during the full sample. For the price of gold the non linear models perform better than the random walk in sample and out of sample. In sample non linear models for the price of silver perform better than the random walk but this predictive capacity is lost out of sample, mainly due to the structural change that occurs (reduction) in the variance of the out of sample models. The in sample and out of sample predictive capacity of the non linear models is reduced when the variables are in logs. Clear and strong evidence is found for a simultaneous relationship between the rates of return of gold and silver. In the three type of relationships that we have analysed between the prices of gold and silver, the dependence is less out of sample, possibly meaning that the two markets are becoming separated. (C) 1998 John Wiley \& Sons, Ltd.
\end{abstract}

KEY WORDS Gold and silver prices; cointegration; bubble; non linear error correction; efficient market hypothesis; out of sample forecast; forecast encompassing 


\section{INTRODUCTION}

Gold and silver have been actively traded for thousands of years and remain important, closely observed markets. Traditionally the ratio of gold to silver prices lay between eight and twenty, suggesting a fairly close long run relationship. Here monthly prices are analysed from the end of 1971, when both price series were deregulated, until mid 1990 using some recently developed time series techniques, including cointegration and linear and non linear error correction models. Data after June 1990 are used to evaluate models. The main objective is to see if there is any evidence of a stable or semi stable long run relationship between these prices that can be useful for forecasting gold and silver prices. We are interested in estimating the contemporaneous relationships between the prices of gold and silver in levels, in logs, in rates of return and in first differences. The simple economics of the situation is not clear, as gold and silver have both distinct and important commercial uses for which there are no substitutes, suggesting that the two markets should be separated. However, elsewhere they do act as quite close substitutes, such as for jewellers and as investments that are used to reduce certain types of risks in portfolios, particularly high inflation risks. These prices are determined in clearly speculative markets and so can be expected to be unit root processes. If they are then cointegrated, the extent to which either can be forecast will be expected to be limited, due to the standard efficient market hypothesis. We check the departures from the pure efficient hypothesis by analysing the dynamic linear and non linear structure of the first difference of the series with the class of error correction models.

There is a feature of this data that makes it particularly interesting, which is the widely known and well documented 'bubble' in silver prices from roughly June 1979 to March 1980. The Hunt brothers, of Texas, and others, appeared to try to corner the silver available for speculation, so that investors who sold short had difficulty in buying silver to deliver at the end of the contract. By August 1979 the Hunt brothers and their collaborators may have owned or had rights to $\$ 2$ billion worth of silver, representing over 250 million ounces. The price of silver rose from $\$ 6$ in 1978 to $\$ 10.61$ on 31 August 1979 , peaking at $\$ 48.70$ on 7 January 1980 and falling back to $\$ 10.80$ on 28 March 1980 . The eventual price reduction occurred after substantial changes in market trading rules. A rather journalistic account of the period can be found in the book Beyond Greed by S. Fay (1982). For convenience this period just will be called 'the bubble' in this paper although it does not completely correspond to the concept of bubble found in the financial literature as its period of existence and the reason for occurrence are known with some accuracy. A plot of the prices against time, as used in this analysis, is shown in Figures 1(a) and 1(c). It is seen that gold prices do increase during and around the bubble, even though the Hunts do not seem to have undertaken any special trading in gold in this period. However, the gold price movement is less spectacular. A further objective of the paper is to investigate the effects of the substantial bubble on the long run relationship and evaluate to what extent non linear error correction models (NECs) can account for the rest.

Figure 2(a) plots the price of gold against the price of silver. The bubble corresponds to the six points in the upper right quadrant. Apart from these points, the remainder do generally lie around lines of a similar slope, although there does seem to be a possible change in intercept in the pre and post bubble period. In the following analysis the 'full sample' period 1971:1 to 1990:6, with 224 observations is analysed and also the 'post bubble' period 1980:4 to 1990:6, having 111 observations. Log prices and price levels are analysed separately. The data is taken from the IMF, International Financial Statistics, the price of gold is \$ per fine ounce, London and the price of silver per troy ounce, New York. 


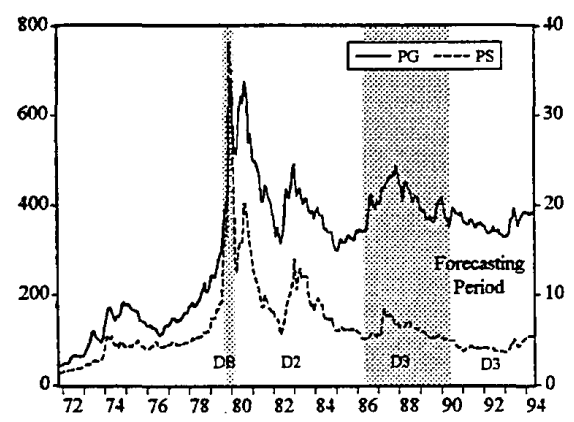

(a)

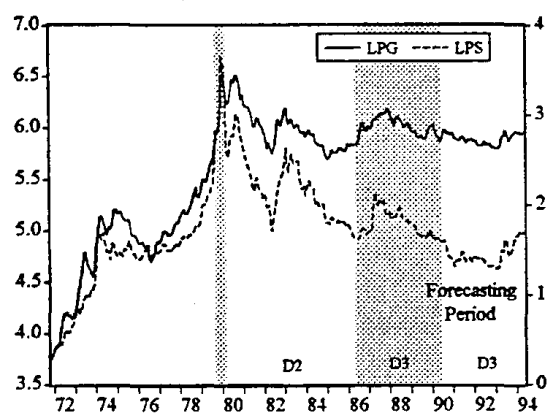

(c)

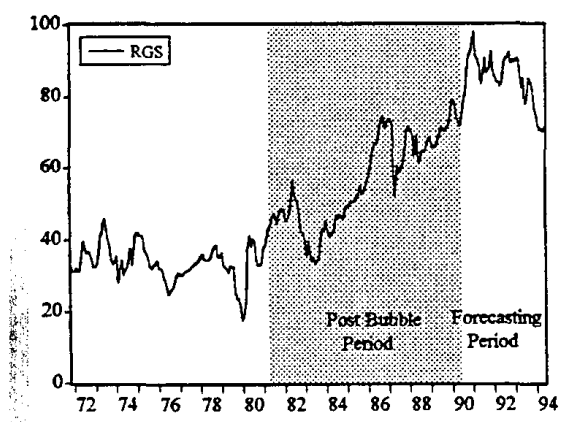

(e)

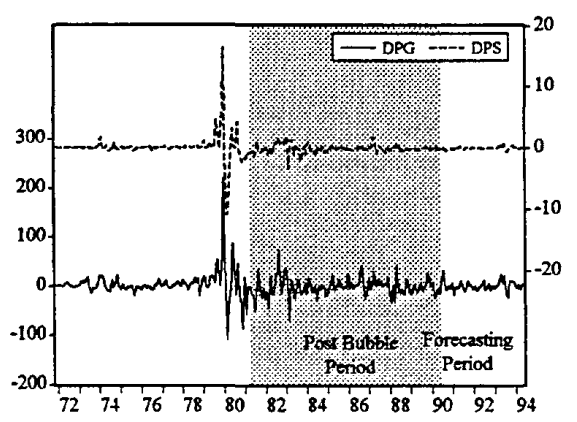

(b)

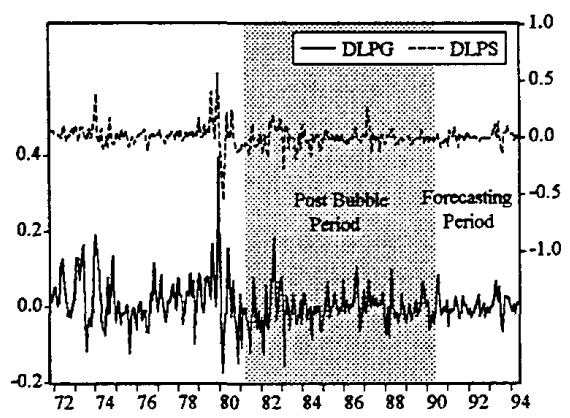

(d)

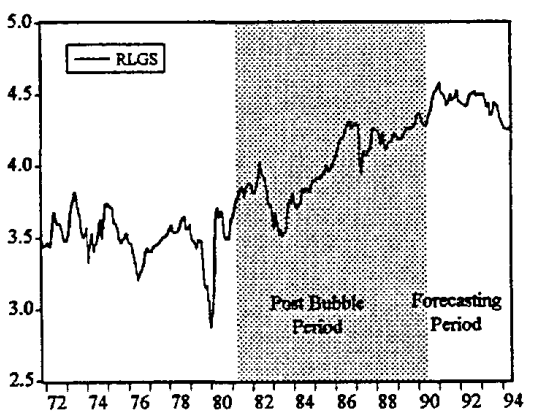

(f)

Figure 1. (a) Price of gold $(P G)$ and price of silver $(P S)$. (b) First differences of the prices of gold $(D P G)$ and silver $(D P S)$. (c) Log of price of gold $(L P G)$ and log of price of silver $(L P S)$. (d) First differences of the log prices of gold $(D L P G)$ and silver $(D L P S)$. (e) Ratio of prices of gold and silver $(R G S)$. (f) Log of the ratio of the price of gold and silver $(L R G S)$ 


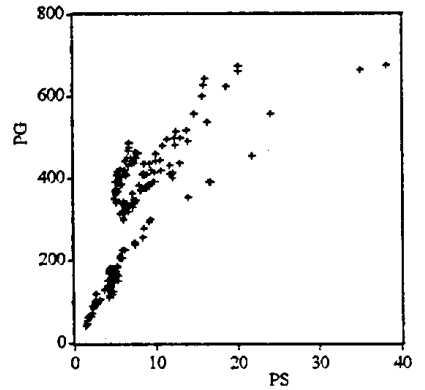

(a)

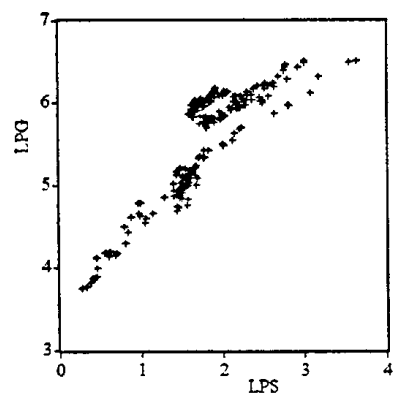

(c)

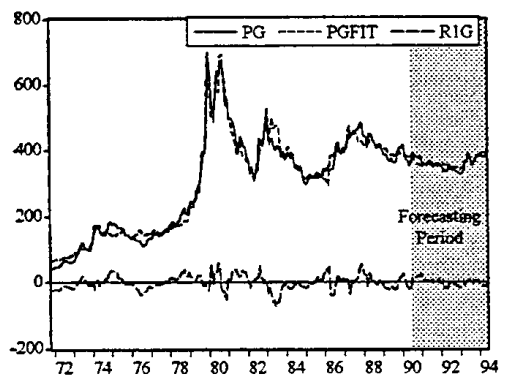

(e)

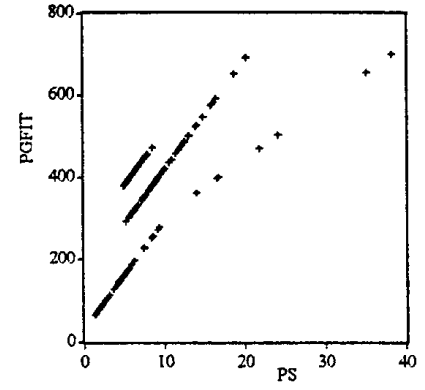

(b)

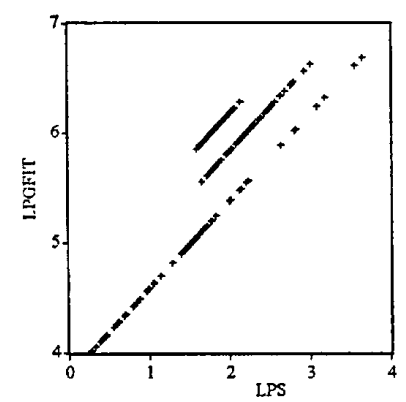

(d)

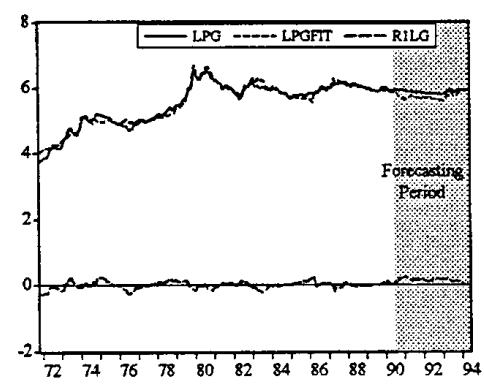

(f)

Figure 2. (a) Cross plot of the price of gold $(P G)$ and the price of silver $(P S)$ from 1971:11 to 1990:06.

(b) Cross plot of the fitted values of $P G$ against the price of silver (PS) from 1971:11 to 1990:06. (c) Crossplot of the log prices of gold ( $L P G$ ) against silver (LPS) from 1971:11 to 1990:6. (d) Cross plot of the fitted values of $L P G$ against the log prices of silver (LPS) from 1971:11 to 1990:6. (e) Long run relationship between the prices of gold and silver: price of gold $(P G)$, fitted values $(P G F I T)$, and residuals $(R l G)$. (f) Long run relationship between the log prices of gold and silver: log price of gold $(L P G)$, fitted values (LPGFIT), and residuals $(R I L G)$ 
The post sample period is 1990:7 to 1994:6, contains 48 terms. The choice of 1990:7 as the starting date is accidental; when the first version of this paper was prepared, only about 15 terms were preserved for the post sample, but delays in completion of the analysis has allowed this post sample size to increase. It does allow for a methodological opportunity, which we have not seen investigated before. In many time series modelling exercises, alternative models are compared by their post sample forecasting ability. One can use forecast encompassing, for example, or the combination of forecasts. However, a possible difficulty that this procedure of post sample evaluation faces is that the generating mechanism for the process could have changed between the in and out of sample, so that a regime shift had occurred. For this data set, we have sufficient post sample data to analyse it and to thus compare the models found with in sample models. The forecasts from the in sample models can then be compared with these post sample models.

The following notation is used: $P G, P S$ for the price of gold and silver; $L X$ for $\log$ of $X, \Delta X$ for difference of $X, X_{k} \equiv X_{t}{ }_{k}$ i.e. $X_{t}$ lagged $k$ time units. Thus, $\Delta L P G{ }_{3}$ is $\Delta \log$ Price Gold $_{t}{ }_{3}$. Three dummies are used in presenting the results:

$\begin{array}{llll}D B & 1 \text { if } t & 1979: 9 \text { to } 1980: 3 & 0 \text { otherwise } \\ D 2 & 1 \text { if } t & 1980: 4 \text { to } 1986: 4 & 0 \text { otherwise } \\ D 3 & 1 \text { if } t & 1986: 5 \text { to } 1990: 6 & 0 \text { otherwise }\end{array}$

Thus $D B$ represents the bubble period, $D 2$ the immediate post bubble period and $D 3$ a later period when a further change in the intercept of the cointegrating relationship (if any) may have occurred. The dummies that mainly affects the intercepts of the cointegrating relationships are shown in Figures 1(a) and 1(c). The three periods used for the dynamic (linear and non linear) analysis are shown in Figures 1(b) to 1(f).

The analysis performed in this paper is quite different from that of two earlier papers that consider gold and silver prices. Chan and Mountain (1988) analyse weekly data, plus and interest rate series for the early 1980s and are concerned with causality questions, using linear models and without consideration of cointegration. They claim to have found a feedback relationship between gold and silver prices and models that out forecast random walks, although this latter statement is not formally tested. Akgiray et al. (1991) look at daily returns for gold and silver for the period 1975 to 1986, where return is the "natural logarithm of the ratio of two successive daily spot prices". They find no forecastability in the means of returns but temporal structure in the variance, which is modelled as a GARCH process. Our results, presented below, are rather different, but are difficult to compare as we use different techniques, time periods, and monthly data. MacDonald and Taylor (1988) do consider cointegration between three monthly metal prices tin, lead, and zinc and find none, but do not look at gold and silver prices.

The structure of the paper is the following. The next section presents the results of estimating the cointegration relationships between the prices of gold and silver in levels and in logs. The third section discusses the selected linear and non linear error correction models for the prices of gold and silver. The same class of models but estimated for the rates of return of gold and silver are presented in the fourth section. The fifth section presents the estimated contemporaneous relationships between the first differences of the two prices and between the two rates of return. The economic intuition of these results is explained in terms of the implications on a normalized portfolio. Conclusions are presented in the sixth section. Finally, in the Appendix there is a discussion about efficient estimation procedures of the three different types of parameters of interest. 
Table I. Price of gold $(P G)$ and price of silver $(P S)$ : long run relationships from 1971:11 to 1990:6

\begin{tabular}{lcccc}
\hline Regressors & $\begin{array}{c}\text { Dependent } \\
\text { variable is } \\
P G\end{array}$ & $\begin{array}{c}\text { Dependent } \\
\text { variable is } \\
P S\end{array}$ & $\begin{array}{c}\text { Dependent } \\
\text { variable is } \\
\log (P G)\end{array}$ & $\begin{array}{c}\text { Dependent } \\
\text { variable is } \\
\log (P S)\end{array}$ \\
\hline Const & 30.1 & 0.52 & 3.8 & 4.28 \\
$P S$ & 26.6 & & & \\
$P G$ & 138.7 & 0.03 & & 0.47 \\
$D B$ & 12.8 & 10.3 & & 0.90 \\
$D B^{*} P S$ & 124.6 & 0.04 & 0.45 & 1.16 \\
$D B^{*} P G$ & 218.4 & 3.55 & 0.79 & 224 \\
$D 2$ & & 7.07 & & 0.95 \\
$D 3$ & & & & \\
$\log (P S)$ & 224 & 224 & 0.97 & 0.26 \\
$\log (P G)$ & 0.98 & 0.97 & 0.25 & $3.78)$ \\
Sample size & 0.50 & $6.58(4.78)$ & $4.25(3.78)$ & $4.5(3)$ \\
$R^{2}$ & $5.59(4.78)^{\mathrm{a}}$ & 6.58 & & \\
DW & & & & \\
DF (unit root test on residuals) & & & & \\
\hline
\end{tabular}

Tests of long run parameter constancy of full sample models (1971:11 to 1990:6) forecasting period is from $1990: 7$ to $1994: 6$

\begin{tabular}{lcccc}
\hline Forecast & 11.94 & 11.08 & 96.96 & 118.2 \\
Chi $^{2}(48)$ & $p$ value 1.0 & $p$ value 1.0 & $p$ value 0.0 & $p$ value 0.0 \\
& \multicolumn{2}{c}{$\begin{array}{c}\text { Unit root test on long run errors: out of sample period } \\
(1990: 7 \text { to 1994:6) }\end{array}$} \\
$\begin{array}{l}\text { DF (no constant and no trend) } \\
\text { DF (with constant and trend) }\end{array}$ & $3.4(1.95)^{\mathrm{b}}$ & $3.3(1.95)$ & $3.5(3.5)$ & $3.3(3.5)$ \\
\hline
\end{tabular}

${ }^{a}$ In parentheses are the $5 \%$ critical values for this particular sample size, obtained from Mackinnon (1991) by counting each regressor, but the intercept, as a new variable.

${ }^{\mathrm{b}}$ In parentheses are the $5 \%$ critical values obtained from Mackinnon (1991), which are the Dickey Fuller critical values but adjusted for this particular sample size.

\section{LONG RUN RELATIONSHIPS}

The variables $P G, P S, L P G$, and $L P S$ were all tested using Dickey Fuller tests in all sample sizes and in all cases the null of $\mathrm{I}(1)$ was not rejected, but details are not shown. The plots in Figures 2(a) and 2(c) are of $P G$ against $P S$ and $L P G$ against $L P S$ indicated apparent linear relationships, but with occasional switches in level (intercept). These switches correspond to the periods captured by the dummies defined above.

Table I shows the long run estimated regressions used to investigate the possible presence of cointegration. The first column has $P G$ as its dependent variable and this is related to $P S$ plus a constant, the dummies defined in the previous section and a product of the bubble dummy and $P S$ in the second column now has $P S$ as the dependent variable, with $P S$ replaced by $P G$ as the explanatory variable and the same dummies. The final two columns investigate similar long run relationships between the logs of the prices of gold and silver. The question of greatest interest is whether or not the residuals are I(1). If this 'equilibrium regression' contained $r$ explanatory I(1) variables, critical values for the Dickey Fuller test, with or without a linear trend, are given by 
MacKinnon (1991) for $r \leqslant 5$. However, our regression is not a traditional one, as each equation contains one regular I(1) variable, two or three dummies and possibly a dummy multiplying the $\mathrm{I}(1)$ variable. It is suggested that the equivalent number of explanatory variables will be either between 1 and 5 for the $P G$ and $P S$ equations and either 1,2, or 3 for the $L P G$ and $L P S$ equations. Using the MacKinnon tables, the $95 \%$ critical values for 1, 2, 3, 4, and 5 explanatory variables are $3.37,3.80,4.17,4.49$, and 4.77 , respectively for $\mathrm{H}_{0}$ : the residual is I(1). For each of the residuals, the null is rejected, in the direction of the residual being $\mathrm{I}(0)$. The results thus suggest several features of the data:

(1) Cointegration appears to be found for the full sample, both for levels and for logs.

(2) The intercept dummies greatly strengthen the cointegration results. Without their use, cointegration is marginal. Fewer dummies are needed for the logs of prices than for the prices. The dummies are largely used to explain the bubble period and its impact on the post bubble period.

If there is cointegration between $P G$ and $P S$, there will be just a single equilibrium relationship, and so it should be possible to solve for the second column of Table I from the first column, by switching the sides of the equation of $P G$ and $P S$. This relation would hold exactly if $R^{2} \quad 1$. Suppose that the first equation is written as

$$
P G \quad c+\theta P S+\beta_{1} D B+\lambda D B \cdot P S+\beta_{2} D 2+\beta_{3} D 3+e
$$

which solves out as

$$
P S \quad \theta^{1} \frac{\left[c+\beta_{1} D B+\beta_{2} D 2+\beta_{3} D 3+P G\right]}{(1+\lambda / \theta \cdot D B)}
$$

From Table I it is seen that $\theta \quad 26.6, \lambda \quad 12.8$, etc. For the period when $D B \quad 0$, it is possible to compare the values given by this formula with those obtained from the full sample regressions, given in Table I.

Regressor
Constant
$P G$
$D 2$
$D 3$

Full-sample
0.52
0.03
3.55
7.07

Derived estimate
1.13
0.04
4.68
8.21

and for the bubble period:
$D B$
10.3
10.4
$D B^{*} P G$
0.04
0.04

A similar exercise with the final two columns of Table I, deriving an equation for $L P S$ from the $L P G$ equation gave the following

$\begin{array}{lcc}\text { Regressor } & \text { Full-sample regressor } & \text { Derived } \boldsymbol{L P G} \text { eqn } \\ \text { Constant } & 4.28 & 4.80 \\ L P G & 1.16 & 1.27 \\ D 2 & 0.47 & 0.57 \\ D 3 & 0.90 & 1.01\end{array}$


The bubble period was not specifically involved with the log price equations as the regressions found the bubble dummies insignificant. The derived equations appear adequately to approxi mate the values found by direct estimation. As these equations have residuals that are not white noises, confidence intervals on the coefficient estimates are not reported, so a formal comparison is not attempted. However, this analysis gives added confidence that the apparent cointegration was actually present at least during part of the in sample period.

Table I also shows the values found for Dickey Fuller tests applied to the errors (parameters are not estimated out of sample) of the equilibrium models when applied to the out of sample period. With 48 terms, the MacKinnon (1991) table suggests a 95\% critical value of 1.94 for the Dickey Fuller test with no constant or trend and 3.42 for this test with a trend for a single series and with no explanatory series, so that the first pair of residual series reject I(1) but the residuals from the log prices do not do so clearly. There is some evidence that the cointegration continues into the post sample, but the evidence is weak for the log price series (compare Figures 2(e) and 2(f)).

Chow forecast test results for parameter constancy are also shown in Table I, finding no further evidence of changes in parameter values for the long run relationships for the levels of the prices of gold and silver, but there are significant changes in the log price relationships (compare also Figures 2(e) and 2(f)). A possible explanation for the results of the test is that the variances of the residuals for the in and out of sample periods are quite different, as will be documented in later sections.

\section{ERROR CORRECTION MODELS FOR THE PRICES OF GOLD AND SILVER}

In this section a number of alternative error correction models are considered with $\triangle P G$ and $\triangle P S$ as the dependent variables, where $\Delta$ denotes difference. Models are estimated over the three time periods identified in the first section, the full sample (1972:12 to 1990:6), the post bubble period (1981:04 to 1990:6), and the post sample period (1990:7 to 1994:6), then the models for the first two periods are used to provide one step forecasts over the post sample period.

Seven different types of model specification were considered. In models 1 to 4 , lags of $\triangle P G$ and $\triangle P S$ were included for consideration, up to lag 10 . These terms were not used in models 5 to 7 . In models $1,3,4$, and 7 the error correction terms $Z_{t}$ entered the model non linearly.

Model 5 is the simplest in form, with no explanatory variable and so corresponds to the random walk model. Model 2 is the standard linear error correction model, using lagged price differences, Model 6 is similar but without the lagged terms. Model 1 uses a cubic in $Z_{t}{ }_{1}$, as used previously by Escribano (1986) (see Figure 3(a)). Model 3 includes terms $Z_{t}{ }_{1} D\left(Z_{t}{ }_{1}>0\right)$ and $Z_{t}{ }_{1} D\left(Z_{t}{ }_{1} \leqslant 0\right)$ where $D(Z>0)$ is a dummy that is one if $Z$ is positive, zero otherwise, which corresponds to putting $Z_{t}, 1$ and its absolute value into the model (see Figure 3(c)). This non linear form of the error correction model has been used by Granger and Lee (1989), for example. Models 4 and 7 use terms $Z_{t}{ }_{1} D\left(\Delta Z_{t}{ }_{1}>0\right)$ and $Z_{t}{ }_{1} D\left(\Delta Z_{t}{ }_{1} \leqslant 0\right)$, which is a form previously used by Escribano and Pfann (1990) (see Figure 3(d)). In every model and for each time period the term $Z_{t}$ is defined as the residual in the corresponding full sample equilibrium model given in Table I. In sample, five specification tests are provided for each model, to test for autocorrela tions in the residuals, up to lag seven, ARCH up to order 7, normality, heteroscedasticity and the Reset test for linearity. Each equation is estimated individually by OLS. As essentially the same explanatory variables are used in both model 1 for $\triangle P G$ and $\triangle P S$, no gain in efficiency would occur from estimating the system, and similarly for other pairs. The coefficients on the lags of 


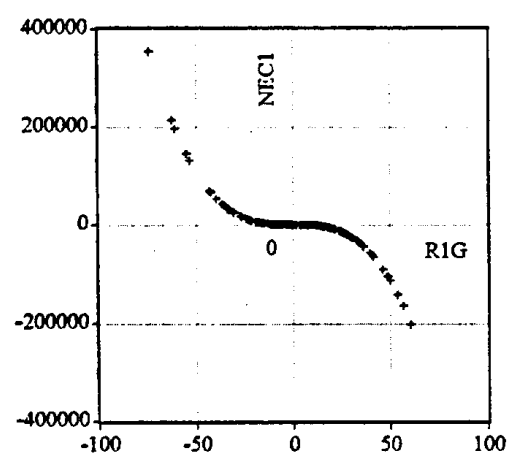

(a)

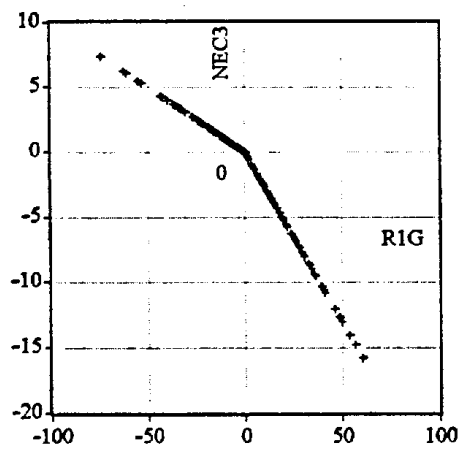

(c)

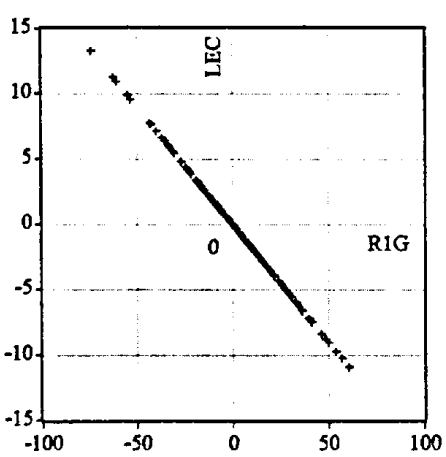

(b)

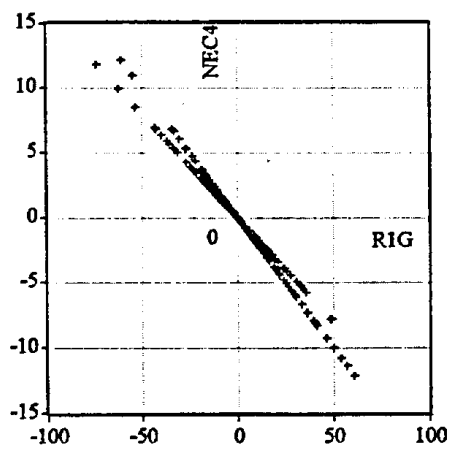

(d)

Figure 3. (a) Non linear error correction (NEC1) (Escribano, 1986): model 1 of Table V(a). (b) Linear error correction (LEC) (Engle and Granger, 1987): model 2 of Table V(a). (c) Non linear error correction (NEC3) (Granger and Lee, 1989): model 3 of Table V(a). (d) Non linear error correction (NEC4) (Escribano and Pfann, 1990): model 4 of Table V(a)

$\Delta P G, \triangle P S$ (or the lags) plus their $t$ values, are not shown to save space. All $t$ values shown are heteroscedastic robust. However, the $t$ values on $Z$ terms are non standard under a null of no cointegration.

Table II(a) shows the estimates of the seven models for the error correction model having $\Delta P G$ as dependent variable, using the full sample period on the top, and below the same specifications are used over the post sample period. Table II(b) similarly shows the estimates for these models for the post bubble period at the top, and underneath the same specification for out of sample. Thus, if a particular group of variables are reported in the model in the top panel, they will be used again in the bottom one. Tables II(c) and II(d) show the identical tables using $\triangle P S$ as the dependent variable. Table II(e) summarizes forecasting evaluations of the four models in sample 
Table II(a). Dependent variable: first difference of the price of gold $(\Delta P G)$

\begin{tabular}{|c|c|c|c|c|c|c|c|}
\hline Regressors & Model 1 & Model 2 & Model 3 & Model 4 & Model 5 & Model 6 & Model 7 \\
\hline \multicolumn{8}{|c|}{ Full sample models (1972:12 to 1990:6) } \\
\hline Constant & $4.7(2.5)^{\mathrm{a}}$ & $1.5(0.9)$ & $3.6(1.9)$ & $1.7(1.1)$ & $1.4(0.8)$ & $1.4(0.8)$ & $1.5(0.8)$ \\
\hline Lags of $\triangle P G$ and $\triangle P S^{\mathrm{b}}$ & Yes & Yes & Yes & Yes & No & No & No \\
\hline$Z_{1} \times 10$ & & $0.6(0.9)$ & & & & $0.3(0.4)$ & \\
\hline$Z^{2}{ }_{1} \times 10^{2}$ & $0.7(3.4)$ & & & & & & \\
\hline$Z^{3}{ }_{1} \times 10^{4}$ & $0.6(2.7)$ & & & & & & \\
\hline$Z_{1} D\left(Z_{1}>0\right)$ & & & $0.2(2.2)$ & & & & \\
\hline \multicolumn{8}{|l|}{$Z{ }_{1} D\left(Z_{1} \leqslant 0\right)$} \\
\hline$Z_{1} D\left(\Delta Z_{1}>0\right)$ & & & & $0.1(1.3)$ & & & $0.04(0.4)$ \\
\hline \multicolumn{8}{|l|}{$Z \quad D(\Delta Z \leqslant 0)$} \\
\hline Sample size & 211 & 211 & 211 & 211 & 211 & 211 & 211 \\
\hline$R^{2}$ & 0.29 & 0.26 & 0.27 & 0.26 & 0.00 & 0.00 & 0.0 \\
\hline DW & 2.04 & 2.03 & 2.02 & 2.03 & 1.61 & 1.6 & 1.6 \\
\hline$\sigma$ & 22.54 & 23.07 & 22.88 & 23.05 & 26.21 & 26.26 & 26.26 \\
\hline $\operatorname{AR}(7), F(7, \quad)$ & 0.24 & 0.43 & 0.47 & 0.42 & 3.47 & 3.47 & 3.46 \\
\hline $\operatorname{ARCH}(7), F(7, \quad)$ & 2.2 & 2.4 & 2.3 & 2.4 & 2.0 & 2.06 & 2.04 \\
\hline Normality, $\mathrm{Chi}^{2}$ (2) & 114.0 & 125.7 & 121.9 & 120.9 & 173.2 & 172.7 & 171.7 \\
\hline Heter. $x_{i}^{2}, \mathrm{~F}(, \quad)$ & 3.35 & 3.6 & 3.5 & 3.5 & & 0.92 & 0.04 \\
\hline Reset, F(1, ) & 0.04 & 0.20 & 0.21 & 0.10 & & 3.30 & 2.83 \\
\hline \multicolumn{8}{|c|}{ Out of sample models (1990:7 to 1994:6) } \\
\hline Constant & $0.5(0.3)^{\mathrm{a}}$ & $1.1(0.1)$ & $2.7(1.6)$ & $1.0(0.8)$ & $0.7(0.4)$ & $0.1(0.1)$ & $1.0(0.8)$ \\
\hline Lags of $\triangle P G$ and $\triangle P S^{\mathrm{b}}$ & Yes & Yes & Yes & Yes & No & No & No \\
\hline$Z_{1}$ & & $0.3(2.7)$ & & & & $0.3(2.8)$ & \\
\hline$Z^{2}{ }_{1} \times 10^{4}$ & $0.6(0.0)$ & & & & & & \\
\hline$Z^{3}{ }_{1} \times 10^{3}$ & $0.7(2.3)$ & & & & & & \\
\hline$Z_{1} D\left(Z_{1}>0\right)$ & & & $0.5(2.2)$ & & & & \\
\hline \multicolumn{8}{|l|}{$Z \quad D(Z \leqslant 0)$} \\
\hline$Z{ }_{1} D(\Delta Z>0)$ & & & & $0.6(3.9)$ & & & $0.6(3.4)$ \\
\hline \multicolumn{8}{|l|}{$Z_{1} D\left(\Delta Z_{1} \leqslant 0\right)$} \\
\hline Sample size & 48 & 48 & 48 & 48 & 48 & 48 & 48 \\
\hline$R^{2}$ & 0.27 & 0.30 & 0.26 & 0.40 & 0.00 & 0.15 & 0.22 \\
\hline DW & 2.09 & 2.00 & 1.92 & 1.83 & 1.76 & 1.72 & 1.70 \\
\hline$\sigma$ & 9.80 & 9.49 & 9.73 & 8.78 & 10.32 & 9.64 & 9.22 \\
\hline $\operatorname{AR}(7), F(7, \quad)$ & 0.48 & 0.41 & 0.44 & 0.82 & 1.04 & 1.15 & 1.15 \\
\hline $\operatorname{ARCH}(7), F(7, \quad)$ & 1.3 & 0.66 & 0.95 & 0.34 & 1.11 & 2.28 & 3.13 \\
\hline Normality, $\mathrm{Chi}^{2}$ (2) & 11.7 & 13.4 & 14.3 & 9.3 & 5.8 & 4.16 & 4.5 \\
\hline Heter. $x_{i}^{2}, \mathrm{~F}(, \quad)$ & 0.54 & 0.56 & 0.49 & 0.68 & & 0.07 & 0.82 \\
\hline Reset, F(1, ) & 0.03 & 0.9 & 1.29 & 2.05 & & 0.01 & 0.31 \\
\hline
\end{tabular}

${ }^{a}$ In parentheses are the absolute values of the $t$ ratios of the coefficients. When homoscedasticity is rejected hetero scedasticity consistent standard errors (HCSEs) are used in the $t$ ratios (White, 1980).

${ }^{\mathrm{b}}$ The terms not reported are the coefficients of $\triangle P G_{7}, \Delta P G_{10}, \Delta P S_{1}, \Delta P S_{2}, \Delta P S_{3}, \Delta P S_{8}, \Delta P S_{10}$. Those coefficients are significant in the full sample but many of them are not in the out of sample period.

(full and post bubble) models. Clearly these tables contain many results, and those to which we wish to draw particular attention are:

(1) There does appear to be some evidence of non linearity in error correction terms in models 1 and 3 for $\Delta P G$ (Table II(a)) and possibly for $\triangle P S$ (Table II(c)) for the full sample. However, no corresponding evidence of non linearity is found in the post bubble and out of sample period models. Models in these latter two periods generally pass the specification tests 
Table II(b). Dependent variable: first difference of the price of gold $(\Delta P G)$

\begin{tabular}{|c|c|c|c|c|c|c|c|}
\hline Regressors & Model 1 & Model 2 & Model 3 & Model 4 & Model 5 & Model 6 & Model 7 \\
\hline \multicolumn{8}{|c|}{ Post bubble models (1981:04 to 1990:6) } \\
\hline Constant & $1.3(0.58)^{\mathrm{a}}$ & $1.8(1.0)$ & $1.8(0.8)$ & $2.4(1.3)$ & $1.3(0.7)$ & $1.3(0.7)$ & $1.3(0.7)$ \\
\hline Lags of $\triangle P G$ and $\triangle P S^{\mathrm{b}}$ & Yes & Yes & Yes & Yes & No & No & No \\
\hline$Z_{1}$ & & $0.2(1.9)$ & & & & $0.06(0.8)$ & \\
\hline$Z^{2}{ }_{1} \times 10^{2}$ & $0.6(2.5)$ & & & & & & \\
\hline$Z^{3}{ }_{1} \times 10^{4}$ & $0.9(2.6)$ & & & & & & \\
\hline$Z_{1} D\left(Z_{1}>0\right)$ & & & $0.37(2.7)$ & & & & \\
\hline \multicolumn{8}{|l|}{$Z D(Z \leq 0)$} \\
\hline$Z_{1} D\left(\Delta Z_{1}>0\right)$ & & & & $0.09(0.8)$ & & & $0.08(0.8)$ \\
\hline$Z{ }_{1} D(\Delta Z \leqslant 0)$ & & & & $0.27(2.0)$ & & & $0.05(0.4)$ \\
\hline Sample size & 111 & 111 & 111 & 111 & 111 & 111 & 111 \\
\hline$R^{2}$ & 0.17 & 0.13 & 0.16 & 0.14 & 0.00 & 0.00 & 0.0 \\
\hline DW & 1.95 & 1.96 & 1.96 & 1.93 & 1.84 & 1.83 & 1.82 \\
\hline$\sigma$ & 18.66 & 19.04 & 18.72 & 19.03 & 19.55 & 19.57 & 19.66 \\
\hline $\operatorname{AR}(7), F(7, \quad)$ & 0.32 & 0.35 & 0.31 & 0.35 & 1.22 & 1.27 & 1.24 \\
\hline $\operatorname{ARCH}(7), F(7, \quad)$ & 1.43 & 1.54 & 1.67 & 1.36 & 3.95 & 4.35 & 4.34 \\
\hline Normality, $\mathrm{Chi}^{2}$ (2) & 6.35 & 7.20 & 8.02 & 5.81 & 24.7 & 28.8 & 28.3 \\
\hline Heter. $x_{i}^{2}, \mathrm{~F}(, \quad)$ & 0.62 & 0.78 & 0.69 & 0.72 & & 0.07 & 0.16 \\
\hline Reset, $\mathrm{F}(1, \quad)$ & 0.33 & 1.73 & 1.10 & 0.79 & & 5.04 & 3.54 \\
\hline \multicolumn{8}{|c|}{ Out of sample models (1990:7 to 1994:6) } \\
\hline Constant & $0.5(0.2)^{\mathrm{a}}$ & $0.1(0.1)$ & $2.5(1.3)$ & $0.9(0.5)$ & $0.7(1.4)$ & $0.1(0.1)$ & $0.9(0.6)$ \\
\hline Lags of $\triangle P G$ and $\triangle P S^{\mathrm{b}}$ & Yes & Yes & Yes & Yes & No & No & No \\
\hline$Z_{1}$ & & $0.3(2.3)$ & & & & $0.3(2.8)$ & \\
\hline$Z^{2}{ }_{1}^{1} \times 10^{4}$ & $0.8(0.0)$ & & & & & & \\
\hline$Z^{3}{ }_{1} \times 10^{3}$ & $0.8(2.0)$ & & & & & & \\
\hline$Z_{1} D\left(Z_{1}>0\right)$ & & & $0.5(1.8)$ & & & & \\
\hline \multicolumn{8}{|l|}{$Z{ }_{1} D(Z, \leqslant 0)$} \\
\hline$Z{ }_{1} D\left(\Delta Z_{1}>0\right)$ & & & & $0.6(3.0)$ & & & $0.6(3.3)$ \\
\hline$Z{ }_{1} D(\Delta Z, \leqslant 0)$ & & & & $0.1(0.6)$ & & & $0.1(0.6)$ \\
\hline Sample size & 48 & 48 & 48 & 48 & 48 & 48 & 48 \\
\hline$R^{2}$ & 0.22 & 0.24 & 0.20 & 0.31 & 0.00 & 0.15 & 0.22 \\
\hline DW & 2.11 & 1.98 & 1.95 & 1.88 & 1.76 & 1.72 & 1.67 \\
\hline$\sigma$ & 10.27 & 10.03 & 10.28 & 9.66 & 10.32 & 9.64 & 9.31 \\
\hline $\operatorname{AR}(7), F(7, \quad)$ & 1.34 & 0.75 & 0.89 & 1.02 & 1.04 & 1.15 & 1.26 \\
\hline $\mathrm{ARCH}(7), \mathrm{F}(7, \quad)$ & 1.04 & 1.48 & 1.23 & 2.76 & 1.11 & 2.28 & 3.11 \\
\hline Normality, $\mathrm{Chi}^{2}$ (2) & 3.14 & 2.66 & 2.11 & 0.84 & 5.78 & 4.16 & 4.52 \\
\hline Heter. $x_{i}^{2}, \mathrm{~F}(, \quad)$ & 0.42 & 0.33 & 0.39 & 0.51 & & 0.07 & 0.77 \\
\hline Reset, $\mathrm{F}(1, \quad)$ & 0.09 & 1.49 & 2.69 & 1.05 & & 0.01 & 0.40 \\
\hline
\end{tabular}

${ }^{a}$ In parentheses are the absolute values of the $t$ ratios of the coefficients. When homoscedasticity is rejected hetero scedasticity consistent standard errors (HCSEs) are used in the $t$ ratios (White, 1980).

${ }^{\mathrm{b}}$ The terms not reported are the coefficients of $\Delta P G_{1}, \Delta P G_{4}, \Delta P G_{5}, \Delta P G_{6}, \Delta P G_{8}, \Delta P S_{1}, \Delta P S_{4}, \Delta P S_{8}$. Those coefficients are significant in the post bubble sample but many of them are not in the out of sample period.

(except normality) whereas for the full sample most models failed the ARCH and heteroscedasticity tests.

(2) For $\triangle P G$, model 1 produced the lowest value of $\sigma$ in both the full and post bubble periods, whereas model 7 produced the lowest $\sigma$ value out of sample. For $\triangle P S$, model 1 gave the lowest $\sigma$ in the full period, models 1 and 3 were equal best in the post bubble period and model 6 was best in the out of sample period. Some of the $\sigma^{2}$ values obtained were not significantly different, as reported below. The non linear error correction terms should be considered as 
Table II(c). Dependent variable: first difference of the price of silver $(\triangle P S)$

\begin{tabular}{|c|c|c|c|c|c|c|c|}
\hline Regressors & Model 1 & Model 2 & Model 3 & Model 4 & Model 5 & Model 6 & Model 7 \\
\hline \multicolumn{8}{|c|}{ Full sample models (1972:12 to 1990:6) } \\
\hline Constant $\times 10$ & $2.0(2.4)^{\mathrm{a}}$ & $0.2(0.2)$ & $4.0(2.6)$ & $1.0(0.9)$ & $0.1(0.1)$ & $0.2(0.1)$ & $5.0(2.7)$ \\
\hline Lags of $\triangle P S$ and $\triangle P G^{\mathrm{b}}$ & Yes & Yes & Yes & Yes & No & No & No \\
\hline$Z_{1}$ & $0.1(0.4)$ & $0.05(0.4)$ & & & & $0.1(0.4)$ & \\
\hline$Z^{2}{ }_{1}$ & $0.3(3.7)$ & & & & & & \\
\hline$Z^{3}{ }_{1}$ & $0.04(0.6)$ & & & & & & \\
\hline$Z_{1} D\left(Z_{1}>0\right)$ & & & $0.6(2.3)$ & & & & $0.55(2.0)$ \\
\hline$Z_{1} D\left(Z_{1} \leqslant 0\right)$ & & & $0.6(1.9)$ & & & & $0.9(1.6)$ \\
\hline$Z_{1} D\left(\Delta Z_{1}>0\right)$ & & & & $0.4(2.0)$ & & & \\
\hline$Z \quad D(\Delta Z \leqslant 0)$ & & & & $0.23(1.0)$ & & & \\
\hline Sample size & 211 & 211 & 211 & 211 & 211 & 211 & 211 \\
\hline$R^{2}$ & 0.41 & 0.33 & 0.37 & 0.35 & 0.00 & 0.00 & 0.06 \\
\hline DW & 1.85 & 2.02 & 1.94 & 2.00 & 1.35 & 1.36 & 1.38 \\
\hline$\sigma$ & 1.41 & 1.50 & 1.45 & 1.48 & 1.789 & 1.790 & 1.74 \\
\hline $\mathrm{AR}(7), \mathrm{F}(7, \quad)$ & 2.36 & 0.16 & 0.42 & 0.18 & 11.55 & 11.0 & 11.76 \\
\hline $\operatorname{ARCH}(7), F(7, \quad)$ & 4.11 & 10.4 & 5.94 & 8.21 & 8.68 & 8.32 & 6.12 \\
\hline Normality, $\mathrm{Chi}^{2}$ (2) & 433.9 & 235.3 & 158.9 & 149.9 & 883.4 & 823.0 & 577.4 \\
\hline Heter. $x_{i}^{2}, \mathrm{~F}(,)$, & 2.63 & 3.66 & 3.00 & 3.14 & & 4.59 & 1.99 \\
\hline Reset, F(1, ) & 4.44 & 12.02 & 9.70 & 12.48 & & 29.28 & 27.87 \\
\hline \multicolumn{8}{|c|}{ Out of sample models (1990:7 to 1994:6) } \\
\hline Constant $\times 10$ & $0.6(1.3)^{\mathrm{a}}$ & $0.2(0.6)$ & $1.0(1.5)$ & $0.4(1.2)$ & $0.1(0.3)$ & $0.2(0.7)$ & $0.6(1.0)$ \\
\hline Lags of $\triangle P S$ and $\triangle P G^{\mathrm{b}}$ & Yes & Yes & Yes & Yes & No & No & No \\
\hline$Z_{1}$ & $0.05(0.3)$ & $0.06(0.6)$ & & & & $0.08(1.2)$ & \\
\hline$Z^{2}{ }_{1}^{1}$ & $0.3(1.3)$ & & & & & & \\
\hline$Z^{3}{ }_{1}$ & $0.03(0.1)$ & & & & & & \\
\hline$Z_{1} D\left(Z_{1}>0\right)$ & & & $0.29(1.1)$ & & & & $0.1(0.8)$ \\
\hline$Z_{1} D\left(Z_{1} \leqslant 0\right)$ & & & $0.24(1.5)$ & & & & $0.2(1.7)$ \\
\hline$Z_{1} D\left(\Delta Z_{1}>0\right)$ & & & & $0.1(1.1)$ & & & \\
\hline$Z_{1} D\left(\Delta Z_{1} \leqslant 0\right)$ & & & & $0.2(1.9)$ & & & \\
\hline Sample size & 48 & 48 & 48 & 48 & 48 & 48 & 48 \\
\hline$R^{2}$ & 0.21 & 0.14 & 0.19 & 0.21 & 0.00 & 0.02 & 0.04 \\
\hline DW & 1.94 & 2.04 & 2.01 & 2.00 & 1.81 & 1.84 & 1.89 \\
\hline$\sigma$ & 0.2322 & 0.2348 & 0.2318 & 0.2288 & 0.2287 & 0.2285 & 0.2292 \\
\hline $\operatorname{AR}(7), F(7, \quad)$ & 0.57 & 0.39 & 0.41 & 1.12 & 0.67 & 0.71 & 0.27 \\
\hline $\mathrm{ARCH}(7), \mathrm{F}(7, \quad)$ & 2.22 & 1.95 & 2.04 & 2.46 & 3.16 & 2.93 & 2.61 \\
\hline Normality, $\mathrm{Chi}^{2}$ (2) & 14.69 & 10.9 & 13.60 & 20.20 & 7.95 & 8.52 & 10.48 \\
\hline Heter. $x_{i}^{2}, \mathrm{~F}(, \quad)$ & 1.39 & 1.53 & 1.48 & 1.28 & & 1.35 & 1.24 \\
\hline Reset, $\mathrm{F}(1, \quad)$ & 0.01 & 0.22 & 0.00 & 0.04 & & 1.05 & 0.29 \\
\hline
\end{tabular}

${ }^{a}$ In parentheses are the absolute values of the $t$ ratios of the coefficients. When homoscedasticity is rejected hetero scedasticity consistent standard errors (HCSEs) are used in the $t$ ratios (White, 1980).

${ }^{\mathrm{b}}$ The terms not reported are the coefficients of $\triangle P S_{1}, \Delta P S_{2}, \Delta P S_{5}, \Delta P S_{7}, \Delta P S_{8}, \Delta P G_{1}, \Delta P G_{7}, \Delta P G_{9}$. Those coefficients are significant in the full sample but many of them are not in the out of sample period.

local approximations to the true non linear specification if it occurs. In particular, if $Z_{t}$ enters a cubic it would produce a non stable difference equation for $x_{t}$, since for large values $Z_{t} \quad$ the cubic polynomial is unbounded, and so would not be appropriate as this series is supposed to be $\mathrm{I}(0)$. However, as an approximation to the unknown non linear function the cubic polynomial is very informative since it can encompass large types of nonlinear adjustments toward the equilibrium (compare Figure 3(a) with 3(c)). 
Table II(d). Dependent variable: first difference of the price of silver $(\triangle P S)$

\begin{tabular}{|c|c|c|c|c|c|c|c|}
\hline Regressors & Model 1 & Model 2 & Model 3 & Model 4 & Model 5 & Model 6 & Model 7 \\
\hline \multicolumn{8}{|c|}{ Post-bubble models (1981:04 to 1990:6) } \\
\hline Lags of $\triangle P S$ and $\triangle P G^{\mathrm{b}}$ & Yes & Yes & Yes & Yes & No & No & No \\
\hline$Z_{1}$ & $0.2(1.6)$ & $0.01(1.4)$ & & & & $0.1(1.2)$ & \\
\hline$Z^{2}{ }_{1}^{1}$ & $0.1(1.8)$ & & & & & & \\
\hline$Z_{1}^{1} D\left(Z_{1}>0\right)$ & & & $0.2(2.0)$ & & & & $0.3(1.8)$ \\
\hline$Z_{1} D\left(Z_{1} \leqslant 0\right)$ & & & $0.05(0.4)$ & & & & $0.1(1.2)$ \\
\hline$Z_{1} D\left(\Delta Z_{1}>0\right)$ & & & & $0.15(1.2)$ & & & \\
\hline$Z_{1} D\left(\Delta Z_{1} \leqslant 0\right)$ & & & & $0.1(0.9)$ & & & \\
\hline Sample size & 111 & 111 & 111 & 111 & 111 & 111 & 111 \\
\hline$R^{2}$ & 0.34 & 0.32 & 0.34 & 0.32 & 0.00 & 0.03 & 0.07 \\
\hline Normality, $\mathrm{Chi}^{2}$ (2) & 17.62 & 21.48 & 20.44 & 21.18 & 41.70 & 34.80 & 28.70 \\
\hline Heter. $x_{i}^{2}, \mathrm{~F}(, \quad)$ & 1.61 & 1.83 & 1.54 & 1.66 & & 3.36 & 2.45 \\
\hline Reset, F(1, ) & 0.23 & 0.01 & 0.00 & 0.00 & & 4.67 & 0.15 \\
\hline \multicolumn{8}{|c|}{ Out-of-sample models (1990:7 to 1994:6) } \\
\hline Constant $\times 10$ & $0.5(1.1)^{\mathrm{a}}$ & $0.2(0.5)$ & $1.0(1.2)$ & $0.3(1.0)$ & $0.1(0.3)$ & $0.2(0.7)$ & $1.0(1.2)$ \\
\hline Lags of $\triangle P S$ and $\triangle P G^{\mathrm{b}}$ & Yes & Yes & Yes & Yes & No & No & No \\
\hline$Z_{1}$ & $0.03(0.2)$ & $0.05(0.4)$ & & & & $0.1(1.2)$ & \\
\hline$Z_{1}^{2}$ & $0.3(1.1)$ & & & & & & \\
\hline$Z_{1}^{3}$ & $0.1(0.4)$ & & & & & & \\
\hline$Z_{1} D\left(Z_{1}>0\right)$ & & & $0.3(0.9)$ & & & & $0.1(0.8)$ \\
\hline $\operatorname{ARCH}(7), F(7, \quad)$ & 1.75 & 1.90 & 1.76 & 1.40 & 3.16 & 2.93 & 2.61 \\
\hline Normality, $\mathrm{Chi}^{2}$ (2) & 7.22 & 3.70 & 6.25 & 7.16 & 7.95 & 8.52 & 10.48 \\
\hline Heter. $x_{i}^{2}, \mathrm{~F}(, \quad)$ & 0.24 & 0.22 & 0.26 & 0.18 & & 1.35 & 1.24 \\
\hline Reset, F(1, ) & 0.29 & 1.56 & 0.39 & 0.38 & & 1.05 & 0.29 \\
\hline
\end{tabular}

* In parentheses are the absolute values of the $t$ ratios of the coefficients. When homoscedasticity is rejected hetero scedasticity consistent standard errors (HCSEs) are used in the $t$ ratios (White, 1980).

${ }^{\mathrm{b}}$ The terms not reported are the coefficients of $\triangle P S_{3}, \Delta P S_{4}, \Delta P S_{7}, \Delta P S_{8}, \Delta P G_{1}, \Delta P G_{3}, \Delta P G_{4}, \Delta P G_{5}, \Delta P G_{6}$, $\triangle P G_{8}$. Those coefficients are significant in the full sample but many of them are not in the out of sample period.

(3) There are clear differences between $\sigma$ values across time periods. To summarize the data, the following shows the median $\sigma$ value over the seven models for different periods:

Full sample

Post bubble sample

Out of sample period

Forecasts from full sample

Forecasts from post bubble models

$\begin{array}{cc}\Delta \text { Price } & \Delta \text { Price } \\ \text { gold } & \text { silver }\end{array}$

23.07

19.04

9.64

10.24

10.32

1.50

0.61

0.23

0.29

0.28
$\Delta$ Log price
gold
0.0613

0.0487

0.0278

0.0284

0.0289
$\Delta$ Log price silver

0.0953

0.0736

0.0507

0.0501

0.0519 
Table II(e). Forecasting evaluation of models for $\triangle P G$ and $\triangle P S$ based on their one step forecast errors from $1990: 7$ to $1994: 6$

\begin{tabular}{|c|c|c|c|c|c|c|c|}
\hline $\begin{array}{l}\text { Forecasting } \\
\text { error criteria }\end{array}$ & Model 1 & Model 2 & Model 3 & Model 4 & Model 5 & Model 6 & Model 7 \\
\hline \multicolumn{8}{|c|}{$\begin{array}{l}\text { Forecasting } \triangle P G \text { with the full sample models of Table II(a) } \\
(1972: 12 \text { to } 1990: 6)\end{array}$} \\
\hline$\sigma$ & 10.40 & 10.36 & 10.19 & 10.24 & 10.32 & 10.17 & 10.16 \\
\hline $\mathrm{SC}$ & 4.74 & 4.74 & 4.70 & 4.71 & 4.73 & 4.70 & 4.70 \\
\hline HQ & 4.72 & 4.71 & 4.68 & 4.69 & 4.70 & 4.67 & 4.67 \\
\hline FPE & 110.41 & 109.59 & 105.98 & 107.13 & 108.73 & 105.61 & 105.40 \\
\hline $\begin{array}{l}\text { Forecast test: } \\
\text { compares models } 7 \text { and } 5\end{array}$ & & & & & & & $\begin{array}{l}26.5 \\
(3.5)\end{array}$ \\
\hline \multicolumn{8}{|c|}{$\begin{array}{l}\text { Forecasting } \triangle P G \text { with the post bubble models of Table } I I(b) \\
(1981: 04 \text { to } 1990: 6)\end{array}$} \\
\hline$\sigma$ & 11.26 & 10.74 & 10.81 & 11.17 & 10.32 & 10.05 & 10.01 \\
\hline SC & 4.90 & 4.81 & 4.82 & 4.89 & 4.73 & 4.67 & 4.67 \\
\hline HQ & 4.88 & 4.78 & 4.80 & 4.86 & 4.70 & 4.65 & 4.64 \\
\hline FPE & 129.38 & 117.72 & 119.29 & 127.41 & 108.73 & 103.10 & 102.24 \\
\hline $\begin{array}{l}\text { Forecast test: } \\
\text { compares models } 7 \text { and } 5\end{array}$ & & & & & & & $\begin{array}{l}10.03 \\
(2.9)\end{array}$ \\
\hline \multicolumn{8}{|c|}{$\begin{array}{l}\text { Forecasting } \triangle P S \text { with the full sample models of Table II(c) } \\
(1972: 12 \text { to 1990:6) }\end{array}$} \\
\hline$\sigma$ & 0.26 & 0.30 & 0.29 & 0.30 & 0.23 & 0.23 & 0.29 \\
\hline $\mathrm{SC}$ & 2.65 & 2.36 & 2.44 & 2.34 & 2.89 & 2.91 & 2.43 \\
\hline HQ & 2.68 & 2.39 & 2.46 & 2.37 & 2.92 & 2.93 & 2.46 \\
\hline FPE & 0.07 & 0.09 & 0.08 & 0.09 & 0.05 & 0.05 & 0.08 \\
\hline $\begin{array}{l}\text { Forecast test: } \\
\text { compares models } 6 \text { and } 5\end{array}$ & & & & & & $\begin{array}{r}0.41 \\
(0.3)\end{array}$ & \\
\hline \multicolumn{8}{|c|}{$\begin{array}{l}\text { Forecasting } \triangle P S \text { with the post bubble models of Table II }(d) \\
(1981: 04 \text { to 1990:6) }\end{array}$} \\
\hline$\sigma$ & 0.29 & 0.29 & 0.28 & 0.28 & 0.23 & 0.24 & 0.23 \\
\hline SC & 2.44 & 2.45 & 2.52 & 2.48 & 2.89 & 2.78 & 2.88 \\
\hline HQ & 2.46 & 2.47 & 2.55 & 2.50 & 2.92 & 2.81 & 2.91 \\
\hline FPE & 0.08 & 0.08 & 0.08 & 0.08 & 0.05 & 0.06 & 0.05 \\
\hline
\end{tabular}

As the price of gold is substantially higher than that of silver, it is hardly surprising that the standard deviations of the residuals for the $\triangle P G$ equations are much larger than those for $\triangle P S$. It is less clear why this inequality is reversed for the log prices. The full sample includes the bubble, which is not completely captured by the simple dummies used in the long run relationship, and so again it is not surprising that $\sigma$ for the full sample is larger than for other periods. However, it is also clear from these results, and also visually from Figures 1(a) to 1(d), that volatility is less during the out of sample period than previous periods.

(4) The results of the out of sample one step forecasting exercises using the models in Tables II(a) (d) are shown in Table II(e). The figures show that in terms of producing low $\sigma$ values from these errors, models 6 and 7 do best for $P G$, with the post sample model superior to the full sample model. Similarly models 5, 6, and 7 are superior for both periods for $P S$. Thus, the models that fit best in sample do not forecast the best. The table also shows the result of testing if the errors from the apparently best forecasting model have a significantly lower variance than the errors from the random walk model (5). The test used is that discussed in Granger and Newbold (1986), Chapter 7, and more recently by Diebold 
and Mariano (1995). If the two sets of errors to be compared are $e_{1 t}, e_{2 t}$, one forms

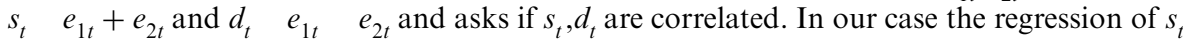
on $d_{t}$ was run and the results in Table II(e) show the coefficient found and its $t$ value. It is seen that for gold the full sample and the post bubble period model 7 forecasts significantly better than the random walk, but no such result is found for silver.

(5) The results of the previous two comments suggest that there could have been a change in parameter values for the models from in to out of sample, including a volatility change, supporting the idea that the two markets are becoming more separated.

\section{ERROR CORRECTION MODELS FOR THE LOG PRICES OF GOLD AND SILVER}

A similar modelling process was conducted using log prices and the results for $\triangle L P G$ dependent variable are shown in Tables III(a) and III(b) and with $\triangle L P S$ as dependent variable in Tables III(c) and III(d) with the forecast evaluations shown in Table III(e). Specification, estimation, and evaluation details are as in the previous section. Some noteworthy features of these results are:

(1) All the models for $\triangle L P G$ have no apparent significant long run structure as all terms involving $Z_{t} \quad$ have low $t$ values. For the $\Delta L P S$ models, there is evidence that $Z_{t}$ i enters significantly, either linearly or possibly non linearly, at least in the full sample. Taken at its face value, these results would be interpreted as saying that $L P G$ and $L P S$ are cointegrated with $L P G$ as the common stochastic trend. The statistical results for the post bubble and the out of sample periods are less clear but are not contradictory to such a conclusion. If $L P G$ is the common stochastic trend, an implication is that there is evidence of a long run causality from log gold prices to log silver prices, according to Granger and Lin (1995). It is possible that this causality was present around the bubble period but not in more recent periods.

(2) In terms of $\sigma$ values, the first four models generally fitted best for the three sample periods for both $L P G$ and $L P S$, so that using lags of $L P G, L P S$ produced an apparently superior model, contrary to a random walk theory. The forecasting results are less clear, for log gold prices models 5 and 6 or 7 provide the best forecasts but there is actually very little to choose between the various models results. For log silver prices, models 2 or 3 provide the best forecasts and generally, models 5, 6, and 7, which use no lag terms, all rank low in their forecasting performance. The significance of the best forecasting model compared to the random walk was tested using the same sum and difference of errors procedure described in the previous section. For $L P G$ no comparison was required as the random walk was the best model for both the full and post bubble periods. For $L P S$ the best models were not found to be significantly better at forecasting than the random walk.

(3) Comparing the $\sigma$ values of the residuals of the out of sample models with those of the one step forecasts shows that there is little gained from the out of sample modelling process, i.e. with this data. Put another way, there seems to be little temporal structure in the post sample period for either $L P G$ or $L P S$, so that both are rather well described as random walks, probably without cointegration. This appears to be a different model from that found for the in sample periods, at least for the LPS.

The tests for parameter constancy were applied to all the error correction models, either for the full or post sample bubble sample periods compared to the post sample period. These tests 
Table III(a). Dependent variable: first difference of the log price of gold $(\triangle L P G)$

\begin{tabular}{|c|c|c|c|c|c|c|c|}
\hline Regressors & Model 1 & Model 2 & Model 3 & Model 4 & Model 5 & Model 6 & Model 7 \\
\hline \multicolumn{8}{|c|}{ Full sample models (1972:12 to 1990:6) } \\
\hline Constant $\times 10^{2}$ & $1.0(1.0)^{\mathrm{a}}$ & $0.4(0.9)$ & $0.4(0.8)$ & $0.4(0.9)$ & $0.8(1.8)$ & $0.8(1.8)$ & $1.0(1.6)$ \\
\hline Lags of $\triangle L P G$ and $\triangle L P S^{\mathrm{b}}$ & Yes & Yes & Yes & Yes & No & No & No \\
\hline$Z_{1} \times 10^{2}$ & $1.0(0.1)$ & $3.0(0.6)$ & & & & $0.04(0.01)$ & \\
\hline$Z^{2}{ }_{1}$ & $0.1(0.6)$ & & & & & & \\
\hline$Z^{3}{ }_{1}$ & $1.2(0.7)$ & & & & & & \\
\hline$Z_{1} D\left(Z_{1}>0\right)$ & & & $0.04(0.6)$ & & & & \\
\hline$Z_{1} D\left(Z_{1} \leqslant 0\right)$ & & & $0.02(0.2)$ & & & & \\
\hline$Z_{1} D\left(\Delta Z_{1}>0\right)$ & & & & $0.05(0.8)$ & & & $0.02(0.4)$ \\
\hline$Z{ }_{1} D(\Delta Z, \leqslant 0)$ & & & & $0.007(0.1)$ & & & $0.03(0.4)$ \\
\hline Sample size & 211 & 211 & 211 & 211 & 211 & 211 & 211 \\
\hline$R^{2}$ & 0.19 & 0.19 & 0.19 & 0.19 & 0.00 & 0.00 & 0.00 \\
\hline DW & 2.03 & 2.02 & 2.02 & 2.03 & 1.41 & 1.41 & 1.42 \\
\hline$\sigma$ & 0.0613 & 0.0611 & 0.0613 & 0.0612 & 0.0666 & 0.0667 & 0.0668 \\
\hline $\operatorname{AR}(7), F(7, \quad)$ & 0.43 & 0.45 & 0.48 & 0.50 & 4.56 & 4.55 & 4.56 \\
\hline $\operatorname{ARCH}(7), F(7, \quad)$ & 1.72 & 1.82 & 1.79 & 1.76 & 1.30 & 1.29 & 1.23 \\
\hline Normality, $\mathrm{Chi}^{2}$ (2) & 43.03 & 42.21 & 42.31 & 43.33 & 47.53 & 47.54 & 45.96 \\
\hline Heter. $x_{i}^{2}, \mathrm{~F}(, \quad)$ & 1.81 & 1.91 & 1.82 & 1.65 & & 1.16 & 0.66 \\
\hline Reset, F(1, ) & 0.12 & 0.26 & 0.23 & 0.17 & & 0.42 & 0.86 \\
\hline \multicolumn{8}{|c|}{ Out of sample models (1990:7 to 1994:6) } \\
\hline Constant $\times 10$ & $0.3(1.4)^{\mathrm{a}}$ & $0.3(2.0)$ & $0.3(2.0)$ & $0.2(1.8)$ & $0.02(0.5)$ & $0.2(1.5)$ & $0.1(1.2)$ \\
\hline Lags of $\triangle L P G$ and $\triangle L P S^{\mathrm{b}}$ & Yes & Yes & Yes & Yes & No & No & No \\
\hline$Z_{1}$ & $0.6(0.9)$ & $0.16(2.0)$ & & & & $0.1(1.4)$ & \\
\hline$Z^{2}{ }_{1}^{1}$ & $5.4(0.9)$ & & & & & & \\
\hline$Z^{3}{ }_{1}$ & $16.1(1.1)$ & & & & & & \\
\hline$Z_{1} D\left(Z_{1}>0\right)$ & & & $0.16(2.0)$ & & & & \\
\hline \multicolumn{8}{|l|}{$Z{ }_{1} D\left(Z_{1} \leqslant 0\right)$} \\
\hline$Z_{1} D\left(\Delta Z_{1}>0\right)$ & & & & $0.2(2.0)$ & & & $0.1(1.5)$ \\
\hline$Z_{1} D\left(\Delta Z_{1} \leqslant 0\right)$ & & & & $0.1(1.3)$ & & & $0.05(0.6)$ \\
\hline Sample size & 48 & 48 & 48 & 48 & 48 & 48 & 48 \\
\hline$R^{2}$ & 0.22 & 0.17 & 0.17 & 0.18 & 0.00 & 0.04 & 0.06 \\
\hline DW & 2.1 & 2.07 & 2.07 & 2.11 & 1.74 & 1.82 & 1.83 \\
\hline$\sigma$ & 0.02765 & 0.02781 & 0.02781 & 0.02795 & 0.02817 & 0.02783 & 0.02791 \\
\hline $\operatorname{AR}(7), F(7, \quad)$ & 1.27 & 1.24 & 1.23 & 1.03 & 1.06 & 1.25 & 1.07 \\
\hline $\operatorname{ARCH}(7), F(7, \quad)$ & 1.89 & 1.68 & 1.68 & 1.76 & 1.00 & 1.16 & 1.21 \\
\hline Normality, $\mathrm{Chi}^{2}$ (2) & 5.74 & 4.00 & 4.00 & 4.65 & 4.91 & 4.44 & 4.34 \\
\hline Heter. $x_{i}^{2}, \mathrm{~F}(, \quad)$ & 0.70 & 0.73 & 0.73 & 0.67 & & 0.80 & 0.99 \\
\hline Reset, F(1, ) & 0.20 & 0.46 & 0.46 & 0.26 & & 0.62 & 0.56 \\
\hline
\end{tabular}

${ }^{a}$ In parentheses are the absolute values of the $t$ ratios of the coefficients. When homoscedasticity is rejected hetero scedasticity consistent standard errors (HCSEs) are used in the $t$ ratios (White, 1980).

${ }^{\mathrm{b}}$ The terms not reported are the coefficients of $\Delta L P G_{1}, \Delta L P G_{6}, \Delta L P G_{7}, \Delta L P G_{11}, \Delta L P S_{2}, \Delta L P S_{11}$. Those coefficients are significant in the full sample but many of them are not in the out of sample period.

typically assume that the variance of the residuals is the same in all periods. However, this seems not to be true here, and if the residual variance is less out of sample than in sample, as found here, the test is biased towards not rejecting the null of no change of parameter values. In all cases, this null was not rejected but this is thought to be a consequence of the test rather than a property of the data in some cases.

Generally, the results for the log prices are quite different, and usually simpler, than those for the levels of prices. The log gold prices are nearly a random walk, and are the long run cause of log silver prices for at least part of the full period. Evidence of a non linear error correction model for 
Table III(b). Dependent variable: first difference of the log price of gold $(\triangle L P G)$

\begin{tabular}{|c|c|c|c|c|c|c|c|}
\hline Regressors & Model 1 & Model 2 & Model 3 & Model 4 & Model 5 & Model 6 & Model 7 \\
\hline \multicolumn{8}{|c|}{ Post bubble models (1981:4 to 1990:6) } \\
\hline Constant $\times 10^{2}$ & $0.3(0.6)^{\mathrm{a}}$ & $0.4(0.8)$ & $0.3(0.4)$ & $0.3(0.6)$ & $0.3(0.7)$ & $0.3(0.7)$ & $0.3(0.6)$ \\
\hline Lags of $\triangle L P G^{\mathrm{b}}$ & Yes & Yes & Yes & Yes & No & No & No \\
\hline$Z_{1} \times 10$ & $0.08(0.1)$ & $0.2(0.5)$ & & & & $0.04(0.8)$ & \\
\hline$Z^{2}{ }_{1} \times 10$ & $0.1(0.2)$ & & & & & & \\
\hline$Z^{3}{ }_{1}$ & $0.5(0.3)$ & & & & & & \\
\hline$Z_{1} D\left(Z_{1}>0\right)$ & & & $0.01(0.2)$ & & & & \\
\hline$Z_{1} D\left(Z_{1} \leqslant 0\right)$ & & & $0.03(0.4)$ & & & & \\
\hline$Z_{1} D\left(\Delta Z_{1}>0\right)$ & & & & $0.001(0.02$ & & & $0.02(0.3)$ \\
\hline$Z{ }_{1} D(\Delta Z \leqslant 0)$ & & & & $0.06(0.6)$ & & & $0.08(0.6)$ \\
\hline Sample size & 111 & 111 & 111 & 111 & 111 & 111 & 111 \\
\hline$R^{2}$ & 0.04 & 0.04 & 0.04 & 0.04 & 0.00 & 0.00 & 0.00 \\
\hline DW & 1.93 & 1.93 & 1.93 & 1.94 & 1.83 & 1.84 & 1.83 \\
\hline$\sigma$ & 0.0488 & 0.0484 & 0.0486 & 0.0485 & 0.0487 & 0.0488 & 0.0490 \\
\hline $\operatorname{AR}(7), F(7, \quad)$ & 0.68 & 0.74 & 0.74 & 0.58 & 1.19 & 1.16 & 1.06 \\
\hline $\operatorname{ARCH}(7), F(7, \quad)$ & 2.93 & 2.99 & 2.99 & 2.75 & 4.51 & 4.23 & 3.86 \\
\hline Normality, $\mathrm{Chi}^{2}$ (2) & 3.41 & 3.33 & 3.33 & 2.65 & 16.36 & 14.02 & 11.44 \\
\hline Heter. $x_{i}^{2}, \mathrm{~F}(,)$, & 2.26 & 3.48 & 2.54 & 2.87 & & 0.08 & 1.85 \\
\hline Reset, F(1, ) & 0.42 & 0.31 & 0.37 & 0.00 & & 0.05 & 1.14 \\
\hline \multicolumn{8}{|c|}{ Out of sample models (1990:7 to 1994:6) } \\
\hline Constant $\times 10$ & $0.2(1.0)^{\mathrm{a}}$ & $0.2(1.4)$ & $0.2(1.4)$ & $0.1(1.2)$ & 0.02 & $0.15(1.5)$ & $0.1(1.2)$ \\
\hline Lags of $\triangle L P G^{\mathrm{b}}$ & Yes & Yes & Yes & Yes & No & No & No \\
\hline$Z_{1}$ & $0.5(0.7)$ & $0.1(1.4)$ & & & & $0.1(1.5)$ & \\
\hline$Z^{2}{ }_{1}^{1}$ & $4.6(0.8)$ & & & & & & \\
\hline$Z^{3}{ }_{1}$ & $13.2(1.0)$ & & & & & & \\
\hline$Z_{1} D\left(Z_{1}>0\right)$ & & & $0.1(1.4)$ & & & & \\
\hline \multicolumn{8}{|l|}{$Z{ }_{1} D\left(Z_{1} \leqslant 0\right)$} \\
\hline$Z_{1} D\left(\Delta Z_{1}>0\right)$ & & & & $0.09(1.4)$ & & & $0.1(1.5)$ \\
\hline$Z_{1} D\left(\Delta Z_{1} \leqslant 0\right)$ & & & & $0.05(0.5)$ & & & $0.05(0.6)$ \\
\hline Sample size & 48 & 48 & 48 & 48 & 48 & 48 & 48 \\
\hline$R^{2}$ & 0.08 & 0.05 & 0.05 & 0.06 & 0.00 & 0.04 & 0.06 \\
\hline DW & 1.95 & 1.92 & 1.92 & 1.92 & 1.74 & 1.82 & 1.83 \\
\hline$\sigma$ & 0.02853 & 0.02838 & 0.02838 & 0.02848 & 0.02817 & 0.02783 & 0.02791 \\
\hline $\operatorname{AR}(7), F(7, \quad)$ & 1.32 & 1.29 & 1.29 & 1.13 & 1.06 & 1.25 & 1.07 \\
\hline $\operatorname{ARCH}(7), F(7, \quad)$ & 0.86 & 0.96 & 0.96 & 1.03 & 1.00 & 1.16 & 1.21 \\
\hline Normality, $\mathrm{Chi}^{2}$ (2) & 4.25 & 3.75 & 3.75 & 3.79 & 4.91 & 4.44 & 4.34 \\
\hline Heter. $x_{i}^{2}, \mathrm{~F}(, \quad)$ & 0.97 & 0.35 & 0.35 & 0.56 & & 0.80 & 0.99 \\
\hline Reset, F(1, ) & 1.97 & 0.00 & 0.01 & 0.00 & & 0.62 & 0.56 \\
\hline
\end{tabular}

${ }^{a}$ In parentheses are the absolute values of the $t$ ratios of the coefficients. When homoscedasticity is rejected hetero scedasticity consistent standard errors (HCSEs) are used in the $t$ ratios (White, 1980).

${ }^{\mathrm{b}}$ The terms not reported are the coefficients of $\triangle L P G_{1}, \Delta L P G_{6}$. Those coefficients are significant in the full sample but none of them are significant in the out of sample period.

$\triangle L P S$ is possible but the evidence is not strong. For price levels, there is stronger evidence for non linear error correction terms, the direction of long run causality is now more likely to be from $P S$ to $P G$ but non linearly. There seems to be clear evidence of time varying coefficients and of volatility through the data period being considered. As the prices get further from the bubble period, volatility decreases, prices become nearer to random walks and cointegration is reduced, possibly lost. The advantage of having a long out of sample period is indicated, as an appropriate time varying coefficient test can be applied. Without this, the problem of the best in sample models producing relatively inferior forecasts would have been unresolvable. 
Table III(c). Dependent variable: first difference of the log price of silver ( $\triangle L P S)$

\begin{tabular}{|c|c|c|c|c|c|c|c|}
\hline Regressors & Model 1 & Model 2 & Model 3 & Model 4 & Model 5 & Model 6 & Model 7 \\
\hline \multicolumn{8}{|c|}{ Full sample models (1972:12 to 1990:6) } \\
\hline Constant $\times 10$ & $0.1(1.3)^{\mathrm{a}}$ & $0.01(0.1)$ & $0.1(1.0)$ & $0.01(0.2)$ & $0.05(0.6)$ & $0.04(0.5)$ & $0.02(0.3)$ \\
\hline Lags of $\triangle L P S$ and $\triangle L P G^{\mathrm{b}}$ & Yes & Yes & Yes & Yes & No & No & No \\
\hline$Z_{1}$ & $0.13(1.4)$ & $0.18(2.8)$ & & & & $0.1(1.6)$ & \\
\hline$Z^{2}{ }_{1}$ & $0.5(1.6)$ & & & & & & \\
\hline$Z^{3}{ }_{1}$ & $0.89(0.7)$ & & & & & & \\
\hline$Z_{1} D\left(Z_{1}>0\right)$ & & & $0.26(2.1)$ & & & & \\
\hline$Z_{1} D\left(Z_{1} \leqslant 0\right)$ & & & $0.1(1.1)$ & & & & \\
\hline$Z_{1} D\left(\Delta Z_{1}>0\right)$ & & & & $0.2(2.0)$ & & & $0.05(0.5)$ \\
\hline$Z{ }_{1} D(\Delta Z, \leqslant 0)$ & & & & $0.16(2.1)$ & & & $0.17(1.9)$ \\
\hline Sample size & 211 & 211 & 211 & 211 & 211 & 211 & 211 \\
\hline$R^{2}$ & 0.23 & 0.22 & 0.22 & 0.22 & 0.00 & 0.02 & 0.03 \\
\hline DW & 2.04 & 2.00 & 2.02 & 2.01 & 1.44 & 1.41 & 1.44 \\
\hline$\sigma$ & 0.0948 & 0.0951 & 0.0951 & 0.0953 & 0.1051 & 0.1042 & 0.1041 \\
\hline $\operatorname{AR}(7), F(7, \quad)$ & 0.85 & 0.80 & 0.81 & 0.82 & 4.50 & 4.81 & 4.75 \\
\hline $\operatorname{ARCH}(7), F(7, \quad)$ & 7.71 & 7.81 & 7.95 & 7.70 & 9.58 & 11.15 & 11.25 \\
\hline Normality, $\mathrm{Chi}^{2}$ (2) & 93.3 & 93.3 & 92.1 & 94.3 & 204.0 & 190.8 & 173.0 \\
\hline Heter. $x_{i}^{2}, \mathrm{~F}(,)$, & 3.81 & 4.72 & 4.22 & 4.10 & & 5.32 & 2.70 \\
\hline Reset, F(1, ) & 1.12 & 2.05 & 1.53 & 2.23 & & 1.86 & 5.36 \\
\hline \multicolumn{8}{|c|}{ Out of sample models (1990:7 to 1994:6) } \\
\hline Constant $\times 10$ & $0.1(0.3)^{\mathrm{a}}$ & $0.3(1.5)$ & $0.3(1.5)$ & $0.4(1.6)$ & $0.2(0.3)$ & $0.1(0.4)$ & $0.1(0.9)$ \\
\hline Lags of $\triangle L P S$ and $\triangle L P G^{\mathrm{b}}$ & Yes & Yes & Yes & Yes & No & No & No \\
\hline$Z_{1}$ & $1.6(1.5)$ & $0.2(1.6)$ & & & & $0.04(0.6)$ & \\
\hline$Z^{2}{ }_{1}^{1}$ & $13.0(1.8)$ & & & & & & \\
\hline$Z^{Z^{3}}{ }^{1}{ }_{1} D(Z,>0)$ & $25.2(1.8)$ & & & & & & \\
\hline$Z{ }_{1} D\left(Z_{1} \leqslant 0\right)$ & & & $0.2(1.6)$ & & & & \\
\hline$Z_{1} D\left(\Delta Z_{1}>0\right)$ & & & & $0.3(1.9)$ & & & $0.16(1.6)$ \\
\hline$Z_{1} D\left(\Delta Z_{1} \leqslant 0\right)$ & & & & $0.17(1.4)$ & & & $0.04(0.5)$ \\
\hline Sample size & 48 & 48 & 48 & 48 & 48 & 48 & 48 \\
\hline$R^{2}$ & 0.30 & 0.23 & 0.23 & 0.25 & 0.00 & 0.00 & 0.06 \\
\hline DW & 2.06 & 2.03 & 2.03 & 2.01 & 1.81 & 1.78 & 2.03 \\
\hline$\sigma$ & 0.0498 & 0.0507 & 0.0507 & 0.0507 & 0.0520 & 0.0525 & 0.0516 \\
\hline $\operatorname{AR}(7), F(7, \quad)$ & 0.76 & 1.26 & 1.26 & 0.58 & 0.62 & 0.60 & 0.54 \\
\hline $\operatorname{ARCH}(7), F(7, \quad)$ & 0.89 & 1.12 & 1.12 & 1.52 & 3.17 & 2.98 & 2.87 \\
\hline Normality, $\mathrm{Chi}^{2}$ (2) & 1.63 & 4.33 & 4.33 & 5.06 & 5.95 & 5.45 & 4.78 \\
\hline Heter. $x_{i}^{2}, \mathrm{~F}(, \quad)$ & 1.06 & 1.57 & 1.57 & 1.21 & & 0.73 & 0.97 \\
\hline Reset, F(1, ) & 0.05 & 0.01 & 0.01 & 0.03 & & 0.04 & 0.21 \\
\hline
\end{tabular}

${ }^{a}$ In parentheses are the absolute values of the $t$ ratios of the coefficients. When homoscedasticity is rejected hetero scedasticity consistent standard errors (HCSEs) are used in the $t$ ratios (White, 1980).

${ }^{\mathrm{b}}$ The terms not reported are the coefficients of $\triangle L P S_{1}, \Delta L P S_{2}, \Delta L P S_{3}, \Delta L P S_{7}, \Delta L P S_{8}, \Delta L P S_{10}, \Delta L P G_{3}$, $\Delta L P G_{7}$. Those coefficients are significant in the full sample but many of them are not in the out of sample period.

\section{SIMULTANEOUS RELATIONSHIPS}

The models discussed in the previous sections have been concerned with temporal relationships and not much of one variable can be explained by its own lags and the lags of other variables. If one takes the best dynamic model for $P G$ and best for $P S$, for some period, then the resulting residuals will be correlated white noises. The extent to which the residuals are correlated could be evidence of the presence of some unobserved 'common factor or feature' that affects both price 
Table III(d). Dependent variable: first difference of the log price of silver $(\triangle L P S)$

\begin{tabular}{|c|c|c|c|c|c|c|c|}
\hline Regressors & Model 1 & Model 2 & Model 3 & Model 4 & Model 5 & Model 6 & Model 7 \\
\hline \multicolumn{8}{|c|}{ Post bubble models (1981:4 to 1990:6) } \\
\hline Constant $\times 10^{2}$ & $0.07(0.08)^{\mathrm{a}}$ & $0.6(0.8)$ & $0.6(0.6)$ & $0.2(0.3)$ & $0.8(1.2)$ & $1.0(1.3)$ & $0.7(0.9)$ \\
\hline Lags of $\triangle L P S$ and $\triangle L P G^{\mathrm{b}}$ & Yes & Yes & Yes & Yes & No & No & No \\
\hline$Z_{1}$ & $0.2(1.5)$ & $0.12(1.8)$ & & & & $0.11(1.5)$ & \\
\hline$Z^{2}{ }_{1}$ & $0.5(1.5)$ & & & & & & \\
\hline$Z^{3}{ }_{1}$ & $0.7(0.4)$ & & & & & & \\
\hline$Z_{1} D\left(Z_{1}>0\right)$ & & & $0.3(1.9)$ & & & & \\
\hline$Z{ }_{1} D(Z, \leqslant 0)$ & & & $0.01(0.1)$ & & & & \\
\hline$Z_{1} D\left(\Delta Z_{1}>0\right)$ & & & & $0.29(2.4)$ & & & $0.2(1.6)$ \\
\hline$Z{ }_{1} D(\Delta Z \leq 0)$ & & & & $0.05(0.7)$ & & & $0.04(0.5)$ \\
\hline Sample size & 111 & 111 & 111 & 111 & 111 & 111 & 111 \\
\hline$R^{2}$ & 0.19 & 0.17 & 0.19 & 0.19 & 0.00 & 0.03 & 0.04 \\
\hline DW & 1.89 & 1.90 & 1.89 & 1.93 & 1.81 & 1.76 & 1.70 \\
\hline$\sigma$ & 0.0732 & 0.0736 & 0.0733 & 0.0730 & 0.0782 & 0.0775 & 0.0772 \\
\hline $\operatorname{AR}(7), F(7, \quad)$ & 0.89 & 0.85 & 1.00 & 0.77 & 1.69 & 1.90 & 1.80 \\
\hline $\operatorname{ARCH}(7), F(7, \quad)$ & 2.09 & 1.87 & 2.14 & 1.44 & 2.26 & 2.29 & 2.18 \\
\hline Normality, $\mathrm{Chi}^{2}$ (2) & 18.0 & 20.2 & 18.9 & 15.01 & 17.9 & 12.0 & 9.33 \\
\hline Heter. $x_{i}^{2}, \mathrm{~F}(,)$, & 0.81 & 1.00 & 0.83 & 0.94 & & 1.29 & 0.91 \\
\hline Reset, F(1, ) & 0.08 & 1.13 & 0.02 & 0.00 & & 2.30 & 0.33 \\
\hline \multicolumn{8}{|c|}{ Out of sample models (1990:7 to 1994:6) } \\
\hline Constant $\times 10$ & $0.2(0.4)^{\mathrm{a}}$ & $0.3(1.2)$ & $0.3(1.2)$ & $0.3(1.3)$ & $0.02(0.7)$ & $0.06(0.3)$ & $0.2(0.9)$ \\
\hline Lags of $\triangle L P S$ and $\triangle L P G^{\mathrm{b}}$ & Yes & Yes & Yes & Yes & No & No & No \\
\hline$Z_{1}$ & $1.4(1.3)$ & $0.16(1.4)$ & & & & $0.04(0.6)$ & \\
\hline$Z^{2}{ }_{1}$ & $10.6(1.5)$ & & & & & & \\
\hline$Z^{Z^{3}}{ }^{1}{ }_{1} D(Z,>0)$ & $19.8(1.5)$ & & & & & & \\
\hline$Z{ }_{1} D\left(Z_{1} \leqslant 0\right)$ & & & $0.16(1.4)$ & & & & \\
\hline$Z_{1} D\left(\Delta Z_{1}>0\right)$ & & & & $0.2(1.7)$ & & & $0.16(1.6)$ \\
\hline$Z_{1} D\left(\Delta Z_{1} \leqslant 0\right)$ & & & & $0.1(1.1)$ & & & $0.04(0.5)$ \\
\hline Sample size & 48 & 48 & 48 & 48 & 48 & 48 & 48 \\
\hline$R^{2}$ & 0.24 & 0.20 & 0.20 & 0.22 & 0.00 & 0.00 & 0.06 \\
\hline DW & 2.06 & 1.96 & 1.96 & 1.99 & 1.81 & 1.78 & 2.03 \\
\hline$\sigma$ & 0.0503 & 0.0505 & 0.0505 & 0.0505 & 0.0520 & 0.0525 & 0.0516 \\
\hline $\operatorname{AR}(7), F(7, \quad)$ & 1.19 & 1.76 & 1.76 & 0.83 & 0.62 & 0.60 & 0.54 \\
\hline $\operatorname{ARCH}(7), F(7, \quad)$ & 0.15 & 0.40 & 0.40 & 0.51 & 3.17 & 2.98 & 2.86 \\
\hline Normality, $\mathrm{Chi}^{2}$ (2) & 2.05 & 4.34 & 4.34 & 4.60 & 5.95 & 5.45 & 4.78 \\
\hline Heter. $x_{i}^{2}, \mathrm{~F}(, \quad)$ & 0.31 & 0.30 & 0.30 & 0.56 & & 0.73 & 0.97 \\
\hline Reset, $\mathrm{F}(1, \quad)$ & 0.26 & 0.13 & 0.13 & 0.08 & & 0.04 & 0.21 \\
\hline
\end{tabular}

${ }^{a}$ In parentheses are the absolute values of the $t$ ratios of the coefficients. When homoscedasticity is rejected heteroscedasticity consistent standard errors (HCSEs) are used in the $t$ ratios (White, 1980).

${ }^{\mathrm{b}}$ The terms not reported are the coefficients of $\triangle L P S_{1}, \Delta L P S_{3}, \Delta L P S_{4}, \Delta L P G_{4}, \Delta L P G_{5}, \Delta L P G_{7}$. Those coefficients are significant in the full sample but many of them are not in the out of sample period.

series during the time span between observations. This factor is often characterized as 'news' in the financial literature.

It is frequent practice to use the return on an asset as the standard measure, defined as $\left(\begin{array}{llll}P_{t} & P_{t} & 1\end{array}\right) / P_{t} \quad 1$ and approximated by $\log P_{t} \quad \log P_{t}{ }_{1}$. The approximation is satisfactory provided that the size of the price change is small compared to the level of the price, but using monthly data and over a volatile period there are several occasions when the approximation is not 
Table III(e). Forecasting evaluation of models for $\triangle L P G$ and $\triangle L P S$ based on their one step forecast errors from 1990:7 to $1994: 6$

\begin{tabular}{|c|c|c|c|c|c|c|c|}
\hline $\begin{array}{l}\text { Forecasting } \\
\text { error criteria }\end{array}$ & Model 1 & Model 2 & Model 3 & Model 4 & Model 5 & Model 6 & Model 7 \\
\hline \multicolumn{8}{|c|}{$\begin{array}{l}\text { Forecasting } \triangle L P G \text { with the full sample models of Table III(a) } \\
(1972: 12 \text { to 1990:6) }\end{array}$} \\
\hline$\sigma$ & 0.0284 & 0.0285 & 0.0284 & 0.0284 & 0.0282 & 0.0282 & 0.0292 \\
\hline $\mathrm{SC}$ & 7.06 & 7.06 & 7.06 & 7.07 & 7.08 & 7.08 & 7.01 \\
\hline HQ & 7.09 & 7.08 & 7.08 & 7.09 & 7.10 & 7.10 & 7.03 \\
\hline FPE & 0.0008 & 0.0008 & 0.0008 & 0.0008 & 0.0008 & 0.0008 & 0.0009 \\
\hline \multicolumn{8}{|c|}{$\begin{array}{l}\text { Forecasting } \triangle L P G \text { with the post bubble models of Table III(b) } \\
(1981: 4 \text { to } 1990: 6)\end{array}$} \\
\hline$\sigma$ & 0.0291 & 0.0291 & 0.0290 & 0.0287 & 0.0282 & 0.0288 & 0.0282 \\
\hline $\mathrm{SC}$ & 7.01 & 7.01 & 7.02 & 7.05 & 7.08 & 7.04 & 7.08 \\
\hline HQ & 7.04 & 7.04 & 7.05 & 7.07 & 7.10 & 7.06 & 7.10 \\
\hline FPE & 0.0009 & 0.0009 & 0.0009 & 0.0008 & 0.0008 & 0.0008 & 0.0008 \\
\hline \multicolumn{8}{|c|}{$\begin{array}{l}\text { Forecasting } \triangle L P S \text { with the full sample models of Table III(c) } \\
(1972: 12 \text { to 1990:6) }\end{array}$} \\
\hline$\sigma$ & 0.0501 & 0.0491 & 0.0495 & 0.0494 & 0.0520 & 0.0523 & 0.0569 \\
\hline $\mathrm{SC}$ & 5.93 & 5.97 & 5.95 & 5.96 & 5.85 & 5.84 & 5.67 \\
\hline HQ & 5.95 & 5.99 & 5.97 & 5.98 & 5.88 & 5.87 & 5.70 \\
\hline FPE & 0.0026 & 0.0025 & 0.0025 & 0.0025 & 0.0028 & 0.0028 & 0.0028 \\
\hline Forecast test: & & 0.46 & & & & & \\
\hline Compares models 7 and 5 & & $(0.8)$ & & & & & \\
\hline \multicolumn{8}{|c|}{$\begin{array}{l}\text { Forecasting } \triangle L P S \text { with the post bubble models of Table III(d) } \\
(1981: 4 \text { to } 1990: 6)\end{array}$} \\
\hline$\sigma$ & 0.0519 & 0.0510 & 0.0506 & 0.0521 & 0.0520 & 0.0522 & 0.0510 \\
\hline $\mathrm{SC}$ & 5.86 & 5.89 & 5.91 & 5.85 & 5.85 & 5.85 & 5.89 \\
\hline HQ & 5.88 & 5.92 & 5.93 & 5.87 & 5.88 & 5.87 & 5.92 \\
\hline \multirow{3}{*}{$\begin{array}{l}\text { FPE } \\
\text { Forecast test: } \\
\text { compares models } 2 \text { and } 5\end{array}$} & 0.0027 & 0.0026 & 0.0026 & 0.0028 & 0.0028 & 0.0028 & 0.0027 \\
\hline & & & 0.47 & & & & \\
\hline & & & $(0.5)$ & & & & \\
\hline
\end{tabular}

acceptable (see Figures 4(a) to 4(d)). Modelling just returns also means that the information in the cointegration between prices will not be properly used.

Tables IV(a) and IV(b) show these results. Using residuals of $\triangle P G$ or $\triangle L P G$, as dependent variables, either for the best model ( 1 for $P G$ or 2 for $L P G$ ) or the random walk (model 5) against the corresponding residual for $\triangle P S$ or $\triangle L P S$ as the explanatory variable using either the best model (3 for $P S$ or 1 for $L P S$ ) or the random walks (model 5). The results are for the full sample and the post bubble period in Table IV(a) and the forecasting period in Table IV(b). Each table shows the coefficient value and associated $t$ value in the regression, the achieved $\sigma$ value, denoted $\sigma_{1}$, and the $\sigma$ value from the original model for the dependent variable, plus the ratio of these last two quantities. The square of this ratio is the amount of the change in the variance achieved; it is roughly $50 \%$ in most cases. The results can be interpreted as saying that the common factor represents approximating $50 \%$ of the variance of $P G$ or $L P G$ in all periods, but the size of the regression coefficient is seen to vary substantially. Generally, the regressions have satisfactory Durbin Watson statistic values.

An alternative interpretation can be given for these results using the log price changes and using $\sigma$ values as measures of risk. If $R_{1 t}, R_{2 t}$ are a pair of return series, consider a normalized portfolio $\alpha_{1} R_{1 t}+\alpha_{2} R_{2 t}$, where $\alpha_{1}^{2}+\alpha_{2}^{2} \quad 1$, and where a negative $\alpha_{i}$ means going short. The 


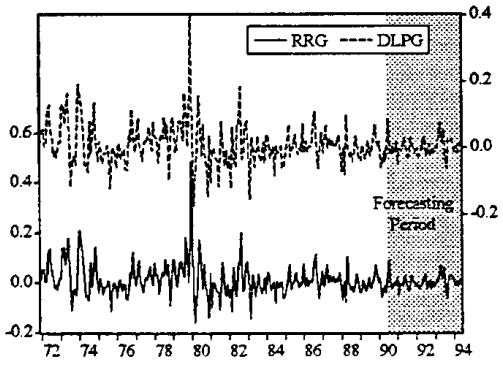

(a)

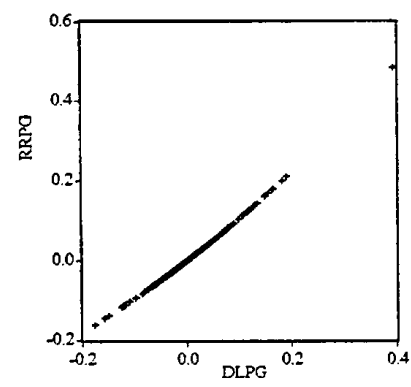

(c)

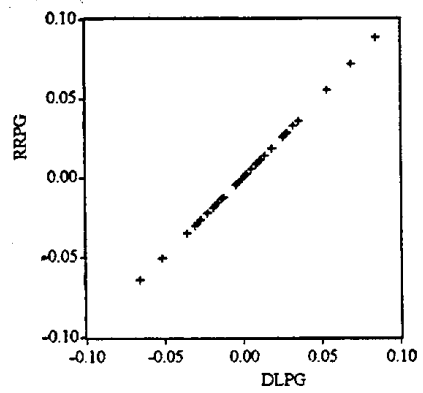

(e)

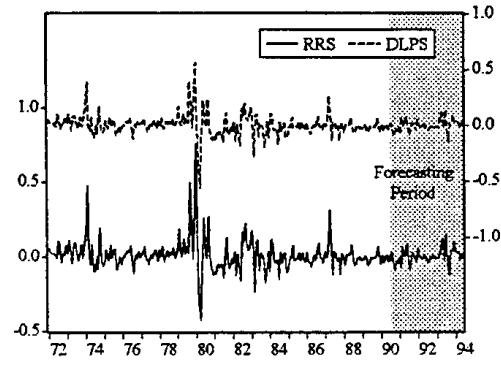

(b)

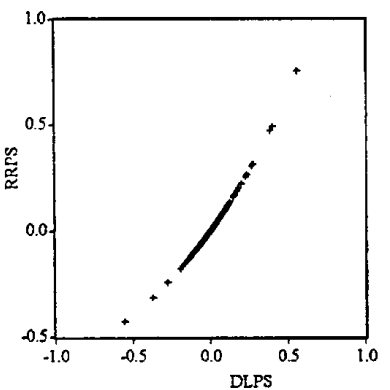

(d)

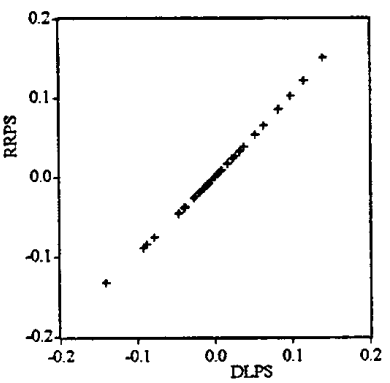

(f)

Figure 4. (a) Rate of return of gold ( $R R G$ ) and the first difference of the log price of gold ( $D L P G)$. (b) Rate of return of silver $(R R S)$ and the first difference of the log price of silver $(D L P S)$. (c) Cross plot of the rate of return of gold $(R R G)$ and the first difference of the log price of gold $(D L P G)$ from 1971:12 to 1990:6. (d) Cross plot of the rate of return of silver $(R R S)$ and the first difference of the log price of silver (DLPS) from 1971:12 to 1990:06. (e) Cross plot of the rate of return of gold $(R R G)$ and the first difference of the log price of gold (DLPG) from 1990:07 to 1994:06. (f) Cross plot of the rate of return of silver $(R R S)$ and the first difference of the log price of silver (DLPS) from 1990:07 to 1994:06 
Table IV(a). Short run relationships between the prices of gold and silver

\begin{tabular}{|c|c|c|c|c|}
\hline \multirow[b]{2}{*}{ Regressors } & \multicolumn{4}{|c|}{ Full sample period (1972:12 to $1990: 6)$ : dependent variable } \\
\hline & $\begin{array}{l}\text { Residuals } \\
\text { of model } 1 \\
(\triangle P G)\end{array}$ & $\begin{array}{l}\text { Residuals } \\
\text { of model } 5 \\
(\triangle P G)\end{array}$ & $\begin{array}{l}\text { Residuals } \\
\text { of model } 2 \\
\Delta L P G\end{array}$ & $\begin{array}{l}\text { Residuals } \\
\text { of model } 5 \\
(\triangle L P G)\end{array}$ \\
\hline $\begin{array}{l}\text { Residuals of } \\
\text { model } 3 \text { of } \triangle P S\end{array}$ & $\begin{array}{c}12.15 \\
(18.04)\end{array}$ & & & \\
\hline $\begin{array}{l}\text { Residuals of } \\
\quad \text { model } 5 \text { for } \triangle P S\end{array}$ & & $\begin{array}{r}11.90 \\
(20.2)\end{array}$ & & \\
\hline $\begin{array}{l}\text { Residuals of } \\
\text { model } 1, \triangle L P S\end{array}$ & & & $\begin{array}{r}0.45 \\
(13.8)\end{array}$ & \\
\hline $\begin{array}{l}\text { Residuals of } \\
\quad \text { model 5, } \triangle L P S\end{array}$ & & & & $\begin{array}{r}0.47 \\
(15.9)\end{array}$ \\
\hline Sample size & 211 & 211 & 211 & 211 \\
\hline$R^{2}$ & 0.61 & 0.66 & 0.48 & 0.55 \\
\hline$\sigma_{1}$ & 13.81 & 15.29 & 0.0434 & 0.0448 \\
\hline $\begin{array}{l}\sigma \\
\text { (Models with } \\
\text { only lagged } \\
\text { variables) }\end{array}$ & $\begin{array}{c}22.54 \\
(\operatorname{model~} 1)\end{array}$ & $\begin{array}{c}26.21 \\
\text { (model 5) } \\
\text { Random walk }\end{array}$ & $\begin{array}{r}0.0611 \\
(\text { model 2) }\end{array}$ & $\begin{array}{c}0.0666 \\
\text { (model 5) } \\
\text { Random walk }\end{array}$ \\
\hline Ratio $\left(\sigma_{1} / \sigma\right)$ & 0.61 & 0.58 & 0.71 & 0.67 \\
\hline Regressors & $\begin{array}{r}\text { Post } \\
\text { Residuals } \\
\text { of model } 1 \\
(\triangle P G)\end{array}$ & $\begin{array}{c}\text { period }(1981: 0 \\
\text { Residuals } \\
\text { of model } 5 \\
(\triangle P G)\end{array}$ & $\begin{array}{l}1990: 6) \text { : depenc } \\
\text { Residuals } \\
\text { of model } 5 \\
(\triangle L P G)\end{array}$ & $\begin{array}{l}\text { variable } \\
\text { Residuals } \\
\text { of model } 5 \\
(\triangle L P G)\end{array}$ \\
\hline $\begin{array}{l}\text { Residuals of } \\
\text { model } 3 \text { of } \triangle P S\end{array}$ & $\begin{array}{l}20.2 \\
(8.9)\end{array}$ & & & \\
\hline $\begin{array}{l}\text { Residuals of } \\
\text { model } 5 \text { for } \triangle P S\end{array}$ & & $\begin{array}{r}19.77 \\
(10.6)\end{array}$ & & \\
\hline $\begin{array}{l}\text { Residuals of } \\
\quad \text { model } 4, \triangle L P S\end{array}$ & & & $\begin{array}{r}0.49 \\
(10.4)\end{array}$ & \\
\hline $\begin{array}{l}\text { Residuals of } \\
\quad \text { model 5, } \triangle L P S\end{array}$ & & & & $\begin{array}{r}0.45 \\
(11.2)\end{array}$ \\
\hline Sample size & 111 & 111 & 111 & 111 \\
\hline$R^{2}$ & 0.41 & 0.50 & 0.49 & 0.53 \\
\hline$\sigma$ & 13.56 & 13.78 & 0.0346 & 0.0333 \\
\hline $\begin{array}{l}\sigma \\
\text { (Models with } \\
\text { only lagged } \\
\text { variables }\end{array}$ & $\begin{array}{c}18.66 \\
(\text { model 1) }\end{array}$ & $\begin{array}{c}19.55 \\
\text { (model 5) } \\
\text { Random walk }\end{array}$ & $\begin{array}{c}0.0487 \\
\text { (model 5) } \\
\text { Random walk }\end{array}$ & $\begin{array}{c}0.0487 \\
\text { (model 5) } \\
\text { Random walk }\end{array}$ \\
\hline Ratio $\left(\sigma_{1} / \sigma\right)$ & 0.73 & 0.70 & 0.71 & 0.66 \\
\hline
\end{tabular}

regressions have considered portfolios of the form $L P G+\lambda L P S$ which transform into a normalized portfolio by taking $\alpha_{1} \quad 1 / \theta$ and $\alpha_{2} \quad \lambda / \theta$, where $\theta^{2} \quad 1+\lambda^{2}$. As $\hat{\lambda}$ is negative, there is a sign interdeterminency, but the case $\alpha_{1}$ positive, $\alpha_{2}$ negative, will be assumed. If the white noise residuals are taken as returns, with zero expectations and if risk is measured by variance, it follows that for the forecasting period, for instance, the risk for the residual of the random model in $L P G$ is 0.00076 , for $L P S$ is 0.00080 , and for the portfolio is 0.00029 . As the expected return 
Table IV(b). Short run relationships between the prices of gold and silver

\begin{tabular}{|c|c|c|c|c|}
\hline \multirow[b]{2}{*}{ Regressors } & \multicolumn{4}{|c|}{ Forecasting period (1990:07 to 1994:6): dependent variable } \\
\hline & $\begin{array}{l}\text { Residuals } \\
\text { of model } 1 \\
(\triangle P G)\end{array}$ & $\begin{array}{l}\text { Residuals } \\
\text { of model } 5 \\
(\triangle P G)\end{array}$ & $\begin{array}{l}\text { Residuals } \\
\text { of model } 1 \\
(\triangle L P G)\end{array}$ & $\begin{array}{l}\text { Residuals } \\
\text { of model } 5 \\
(\triangle L P G)\end{array}$ \\
\hline $\begin{array}{l}\text { Residuals of } \\
\text { model } 5 \text { of } \triangle P S\end{array}$ & $\begin{array}{c}24.80 \\
(5.4)\end{array}$ & & & \\
\hline $\begin{array}{l}\text { Residuals of } \\
\text { model } 5 \text { for } \triangle P S\end{array}$ & & $\begin{array}{l}31.10 \\
(6.5)\end{array}$ & & \\
\hline $\begin{array}{l}\text { Residuals of } \\
\text { model 2, } \triangle L P S\end{array}$ & & & $\begin{array}{c}0.40 \\
(7.2)\end{array}$ & \\
\hline $\begin{array}{l}\text { Residuals of } \\
\quad \text { model 5, } \triangle L P S\end{array}$ & & & & $\begin{array}{r}0.37 \\
(6.4)\end{array}$ \\
\hline Sample size & 48 & 48 & 48 & 48 \\
\hline$R^{2}$ & 0.39 & 0.47 & 0.53 & 0.46 \\
\hline$\sigma_{1}$ & 7.15 & 7.48 & 0.0171 & 0.021 \\
\hline$\sigma$ & 9.80 & 10.32 & 0.0276 & 0.0282 \\
\hline (Models with only & (model 1) & (model 5) & (model 1) & (model 5) \\
\hline lagged variables) & Table II(a) & Random walk & Table II(a) & Random walk \\
\hline Ratio $\left(\sigma_{1} / \sigma\right)$ & 0.73 & 0.72 & 0.62 & 0.74 \\
\hline
\end{tabular}

Table IV(c). Relationship between the rate of return of gold $(R R G)$ and the rate of return of silver $(R R S)$

\begin{tabular}{lccc}
\hline & & Dependent variable & \\
Regressors & $R R G$ & RRG & RRG \\
\hline$R R S$ & $(1971: 12$ to $1990: 06)$ & $(1981: 04$ to $1990: 06)$ & $(1990: 07$ to $1994: 06)$ \\
\hline Sample size & 0.49 & 0.45 & 0.37 \\
$R^{2}$ & $(17.4)$ & $(11.0)$ & $(6.3)$ \\
$\sigma_{1}$ & 211 & 111 & 48 \\
& 0.59 & 0.53 & 0.46 \\
& 0.0455 & 0.0338 & 0.0210 \\
\hline
\end{tabular}

is still zero, there is seen to be a substantial reduction in risk from buying gold and going short on silver, for the full sample. The risk is further reduced to 0.00021 if the best in sample models are used (model 1 for gold, model 2 for silver).

\section{CONCLUSIONS}

In this paper we have analysed the relationships between gold and silver prices particularly from the forecasting viewpoint. We have studied the influence of the large bubble from 1979:9 to 1980:3 on the cointegration relationship and found evidence of cointegration but with different intercepts during the bubble and after the bubble periods. For the prices of gold and silver we have studied whether alternative non linear error correction formulations can beat the random walk, in terms of out of sample forecastability. Furthermore, we have studied the simultaneous relationship between the rates of return of gold and silver and between the first difference of the two prices. Different efficient estimation techniques are required for each of the three questions and this is explained in the Appendix with a simple bivariate cointegrating system. 
With monthly data from 1971 to 1990 , it is found that cointegration could have occurred during some periods and specially during the bubble and post bubble period. In sample non linear models for silver perform better than the random walk but this predictive capacity is lost out of sample, mainly due to the structural change that occurs with a reduction in the variance of the models during the out of sample period. For gold the non linear models perform better in sample and out of sample. The in and out of sample predictive capacity of the non linear models is reduced when the models are logs.

That gold and silver prices have been strongly related is evident from their behaviour during the bubble period. The long run relationship appears to be complicated and one that varies at particular dates. One gets a rather different view of how the series are linked by looking at the levels or the logs of the prices.

Table IV(e) shows the strong simultaneous relationship found by a simple linear regression using the actual return of gold as the dependent variable and a constant and the return on silver as the explanatory variable, for each of the three periods. The regression coefficient is clearly lower in the out of sample period and the standard deviation of the equations residual is the same as for the final column of Table IV(b), suggesting that in this last period the change in log prices is a close approximation to the return (see Figures 4(e) and 4(f)).

If one assumes that a particular model, such as for log price of silver, is correctly specified and has Gaussian residuals, it is possible to derive the model for the price of silver, and hence its error correction model. However, the usual presence of non normal residuals, the frequent presence of heteroscedasticity, and the reality of possible model mis specification makes such exercise of little value. It does seem that the bubble period had a lasting influence on cointegra tion, on the short run dynamics and possibly on the non linearity of the relationship. The most recent period in the data set has been the least volatile, follows models most closely agreeing with the efficient market theory, and has the ratio of gold to silver prices, at over 60 at the time of writing, at historically high levels, possibly suggesting that some separation of the two markets is occurring (see Figures 1(e) and 1(f)).

Many econometricians argue that a post sample evaluation of models is potentially a useful exercise, and we support that proposition. However, if the structure of the model is changing through time, it is more difficult to evaluate the relevance of the models derived in sample, and this does seem to be a property of the data being analysed in this paper. This also makes forecasting particularly difficult. We are convinced that this is an interesting data set to be used as a benchmark for comparing different methodologies and different non linear models. Furthermore, we believe that to consider the possibility of having non linear cointegration relationships seem to be promising with this data set but this suggestion opens interesting and difficult questions for future research.

\section{APPENDIX: EFFICIENT PARAMETER ESTIMATION IN A BIVARIATE COINTEGRATED SYSTEM}

Consider the following error correction (EC) data generating process (DGP):

$$
\begin{array}{cccccc}
\Delta P G_{t} & a_{11} \Delta P G_{t} & 1 & +a_{12} \Delta P S_{t} & 1 & \delta_{g}\left(\begin{array}{llll}
P G_{t} & 1 & \beta P S_{t} & 1
\end{array}\right)+\varepsilon_{g t} \\
\Delta P S_{t} & a_{21} \Delta P G_{t} & 1 & +a_{22} \Delta P S_{t} & 1 & \delta_{s}\left(\begin{array}{lllll}
P_{t} & 1 & \beta^{1} P G_{t} & 1
\end{array}\right)+\varepsilon_{s t}
\end{array}
$$

where the $2 \times 1$ vector $\varepsilon$ is i.i.d. $\mathrm{N}(0, \Omega)$. 
Alternatively we can say that

$$
\varepsilon_{g t} \quad \alpha \varepsilon_{s t}+v_{t}
$$

with orthogonal zero mean elements, $\operatorname{cov}\left(\varepsilon_{s t}, v_{t}\right) \quad 0$.

The cointegrating vector (with long run parameters) is unique and equal to $(1, \quad \beta)$, the contemporaneous relationship (short run parameter) is measured by $\alpha$, and the coefficients of the dynamic terms have all the information about Granger causality in the short run $\left(a_{12}, a_{21}\right)$ and Granger causality in the long run $\left(\delta_{g}, \delta_{s}\right)$.

The above system can be written in two interesting equivalent ways that would allow us to discuss alternative well known estimation procedures and to emphasize the advantages and disadvantages of each.

By direct substitution of equation (A1c) in (A1a) one gets the following system of equations with orthogonal errors:

$$
\begin{aligned}
& \Delta P G_{t} \quad a_{11} \Delta P G_{t} 1_{1}+a_{12} \Delta P S_{t} \quad 1 \quad \delta_{g}\left(\begin{array}{llll}
P G_{t} & 1 & \beta P S_{t} & 1
\end{array}\right)+\alpha \varepsilon_{s t}+v_{t} \\
& \Delta P S_{t} \quad a_{21} \Delta P G_{t}{ }_{1}+a_{22} \Delta P S_{t} \quad 1 \quad \delta_{s}\left(P S_{t} \quad 1 \quad \beta \quad{ }^{1} P G_{t}{ }_{1}\right)+\varepsilon_{s t}
\end{aligned}
$$

Alternatively one can form a linear combination of the two first equations multiplying equations (A1a) and (A1b) by the vector $(1, \quad \alpha)$ giving the following two equation system:

$$
\begin{aligned}
& \Delta P G_{t} \quad a_{11}^{*} \Delta P G_{t} 1_{1}+a_{12}^{*} \Delta P S_{t} 1_{1} \quad \delta_{g}^{*}\left(\begin{array}{lllll}
P G_{t} & 1 & \beta P S_{t} & 1
\end{array}\right)+\alpha \Delta P S_{t}+v_{t} \\
& \Delta P S_{t} \quad a_{21} \Delta P G_{t}{ }_{1}+a_{22} \Delta P S_{t}{ }_{1} \quad \delta_{s}\left(P S_{t} 1^{1} \quad \beta{ }^{1} P G_{t 1}\right)+\varepsilon_{s t}
\end{aligned}
$$

where $a_{11}^{*} \quad\left(a_{11} \quad \alpha a_{21}\right)$ and $a_{12}^{*} \quad\left(a_{12} \quad \alpha a_{22}\right)$.

In what follows, fully efficient estimation methods will be briefly discussed. The first possibility is to use system of equation methods, such as full information maximum likelihood (FIML) on equations (A1a) and (A1b) (see Johansen, 1988). Notice that since there is a parameter restriction $(\beta)$ between the two equations of the system that invalidates estimating it by one step single equation methods (such as NLS) even when all the equations have the same regressors.

Engle and Granger's (1987) two step estimator with the later improvement of Engle and Yoo's (1991) three step estimator solved the inefficiency problem of one step single equation methods. In the first step, the cointegrating vector $(1, \quad \beta)$ is superconsistently estimated (although not efficiently) by OLS in the equation

$$
P G_{t} \quad \beta P S_{t}+u_{t}
$$

In the second step, the lagged residuals are introduced in equations (A1a) and (A1b) since by doing that we are imposing the cross equation parameter restriction and it is now, when the system has the same regressors in all the equations, that system of equations estimation methods are reduced to single equation ones (OLS in each equation of the second step).

In the third step of Engle and Yoo (1991), the OLS estimator of $\beta$ is made efficient, and less biased, by correcting it using the estimated coefficient $\left(c_{1}\right)$ obtained from the OLS regression of

$$
\varepsilon_{g t} \quad c_{1} P S_{t}{ }_{1}+\omega_{t}
$$


In the empirical application used by Engle and Yoo (1991) they estimate the second step in the system (A3a) and (A3b). However, it is important to realize that by doing this the economic interpretation of the coefficients of equation (A3a) might change. Those changes can be especially important if in equation (A1a) the coefficient $a_{12} \quad 0$ and in (A1b) $a_{22} / 0$, because we can even get the wrong direction of the short run Granger causality.

To avoid that problem one has two alternative and equivalent single equation procedures. First, as is usual, estimate the cointegrating vector by OLS in equation (A4). Take those residuals lagged once and form the error correction terms of equations (A1a) and (A1b). Second, estimating the parameters of those equations $\left(a_{11}, a_{12}, a_{21}, a_{22}, \delta_{g}\right.$, and $\left.\delta_{g}\right)$ by OLS is fully efficient since all the equations have same regressors. Third, estimate the parameter $\alpha$ of equation (A1c) by substituting the unknown errors $\left(\varepsilon_{g t}\right.$ and $\left.\varepsilon_{s t}\right)$ by the residuals of the regressions from the second step (this is the estimation procedure implemented in this paper). Fourth, calculate the efficient estimator of the cointegrating vector by transforming its OLS estimate by the coefficient $\left(c_{1}\right)$ obtained by running the regression (A5) but with the residuals $v_{t}$ as the dependent variable.

The other equivalent procedure is to estimate the first step as usual and in the second step, estimate only the parameters of equation (A2b) to get the residuals $\varepsilon_{s t}$. In the third step, one estimates equation (A2a) with the residuals, $\varepsilon_{s t}$, of (A2b) as a new regressor. In the fourth and final step, equation (A5) is estimated to obtain the correction of the OLS estimated cointegrating vector.

The main advantages of these last two fully efficient estimation procedures are that they:

(1) Always estimate directly the parameters of interest

(2) Directly get from the usual econometric packages their corresponding standard errors

(3) Avoid getting wrong short run Granger causality conclusions

(4) Always use single equation methods that do not depend on weak exogeneity conditions

(5) Do not need to become involved in the specification of the full dynamic systems of equations.

\section{ACKNOWLEDGEMENTS}

This paper was written while the first author was visiting the Department of Economics at UCSD and he acknowledges financial support from the Spanish Ministry of Education and Science grants PR94 137 and PB93 0234. The second author was supported by NSF grant SBR93 08295.

\section{REFERENCES}

Akgiray, V., Booth, G. G., Hatem, J. J. and Mustafa, C., 'Conditional dependence in precious metal prices', The Financial Review, 26 (1991) 36786.

Chan, M. W. L. and Mountain, D. C., 'The interactive and causal relationships involving precious metal price movements', Journal of Business and Economic Statistics, 6 (1988) 6977.

Diebold, F. X. and Mariano, R. S., 'Comparing predictive accuracy', Journal of Business and Economic Statistics, 13 (1995) 25364.

Engle, R. F. and Yoo, B. S., 'Cointegrated economic time series: an overall with new results', Chapter 12, 237266 of Long Run Economic Relationships ed. by R. F. Engle and C. W. J. Granger. Oxford University Press, 1991.

Escribano, A., Nonlinear Error Correction: The Case of the Money Demand in the U.K. (1878 1970), PhD dissertation UCSD, Chapter IV, 1986, 11069. 
Escribano, A. and Pfann, G., 'Nonlinear error correction, asymmetric adjustment and cointegration', Working Paper, Universidad Carlos III de Madrid, 1991, 9120.

Fay, S., Beyond Greed, New York: Viking Press, 1982.

Granger, C. W. J. and Lee, T. W., 'Investigation of production, sales, and inventory relationships using multicointegration and nonsymmetric error correction models', Journal of Applied Econometrics, $\mathbf{4}$ (1989), S145 59.

Granger, C. W. J. and Lin, J., 'Causality in the long run', Econometric Theory, 11 (1995), 53036.

Granger, C. W. J. and Newbold, P., Forecasting Economic Time Series, 2nd edition, San Diego, CA: Academic Press, 1986.

MacDonald, R. and Taylor, M., 'Metal prices, efficiency and cointegration: some evidence from the London Metal Exchange', Bulletin of Economic Research, 40 (1988), 23539.

MacKinnon, J., 'Critical values for cointegration tests', in Engle, R. F. and Granger, C. W. J. (eds), Long Run Economic Relationships, Oxford: Oxford University Press, 1991.

White, H., 'A heteroskedasticity consistent covariance matrix estimator and a direct test for hetero skedasticity', Econometrica, 48 (1980) 31738.

Authors' biographies:

Alvaro Escribano is Associate Professor of the Department of Statistics and Econometrics, Universidad Carlos III de Madrid. He has published two books and several papers in the area of time series, non linear models, cointegration, and non linear error correction models with applications to money demand, investment demand, and import and export demands.

Clive W. J. Granger is in the Department of Economics, University of California, San Diego from 1974. $\mathrm{He}$ has a $\mathrm{PhD}$ and an honorary DSc from the University of Nottingham and an honorary DSc from Carlos III University of Madrid. He is a Fellow of the American Academy of Arts and Sciences. His interests are in econometrics and methodology.

Authors' addresses:

Alvaro Escribano, Department of Statistics and Econometrics, Universidad Carlos III de Madrid, C/Madrid, 126, 28903 GETAFE (Madrid), Spain.

Clive W. J. Granger, Department of Economics, University of California, San Diego, 9500 Gilman Drive, La Jolla, CA 92093 0508, USA. 